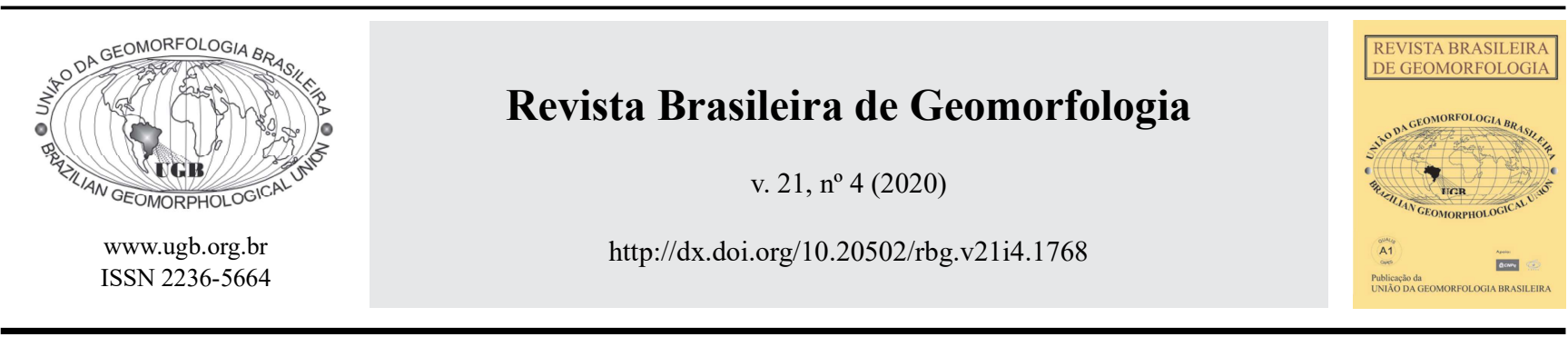

\title{
MÉTODO GEOMORFOMÉTRICO PARA MAPEAMENTO DE TOPOS, CRISTAS E VALES
}

\section{GEOMORPHOMETRIC METHOD FOR MAPPING TOPS, RIDGES AND VALLEYS}

\author{
Ricardo Michael Pinheiro Silveira \\ Departamento de Geografia, Universidade Federal do Paraná \\ Rua Cel. Francisco H. dos Santos s/n, Curitiba, Paraná, CEP: 81531980, Brasil \\ ORCID: https://orcid.or/0000-0002-5664-7079 \\ Email: ricardomichaelps@gmail.com \\ Claudinei Taborda da Silveira \\ Departamento de Geografia, Universidade Federal do Paraná \\ Rua Cel. Francisco H. dos Santos s/n, Curitiba, Paraná, CEP: 81531980, Brasil \\ ORCID: https://orcid.org/0000-0001-6289-6306 \\ Email: claudineits@ufpr.br
}

\section{Informações sobre o Artigo}

Recebido (Received): 06/09/2019

Aceito (Accepted):

$14 / 04 / 2020$

\section{Palavras-chave:}

Modelo Digital do Terreno; MDT; Mapeamento Geomorfológico; Geomorfometria; Classificação de formas do relevo.

\section{Keywords:}

Digital Terrain Model; DTM; Geomorphological mapping; Geomorphometry; Landform classification.

\section{Resumo:}

O mapeamento de feições e processos geomorfológicos, recentemente, tem sido favorecido pelo uso de técnicas geomorfométricas amparadas pelo desenvolvimento da análise digital do relevo. Nesse contexto, o presente trabalho propõe um método para a identificação de topos (convexos e aguçados), segmentos de cristas e vales (planos, abertos ou fechados) com o emprego de três atributos geomorfométricos derivados de um Modelo Digital do Terreno (MDT): a) área de contribuição (calculada pelo método D-Infinito), b) Black Top Hat (BTH) e c) White Top Hat (WTH). O cálculo do Top Hat contempla uma análise de vizinhança regional dos valores de elevação, com uma função de abertura (extração de vales, pelo BTH) e fechamento (extração de topos, pelo WTH). Adotou-se o estado do Paraná (Brasil) como área de estudo para a aplicação da proposta pela sua diversidade geomorfológica. Foi utilizado um MDT com resolução espacial de $20 \mathrm{~m}$, obtido pela interpolação de curvas de nível, pontos cotados e hidrografia, com uso do método Topogrid. A modelagem considerou uma classificação orientada a objeto, a partir da definição das feições a serem modeladas (modelo conceitual) e da referência amostral de ocorrência de tais objetos na paisagem (modelo heurístico), definindo- 
se, assim, os parâmetros geomorfométricos para a representação dos mesmos. As feições derivadas da aplicação da proposta foram condizentes tanto às características regionais do relevo quanto às locais, atestadas por meio de trabalhos de campo realizados em todo o estado do Paraná. A exatidão global do mapeamento foi de $94,4 \%$. Destaca-se a potencialidade do método apresentado como ferramenta de apoio para trabalhos de mapeamento geomorfológico, cuja parametrização confere a possibilidade de replicação metodológica e de diminuição da subjetividade nas etapas operacionais. Reforça-se, também, que o processamento e a qualidade do MDT interferem diretamente nos resultados e que os parâmetros podem ser adaptados conforme os objetivos do mapeamento e da configuração da paisagem do recorte geográfico.

\begin{abstract}
:
The mapping of landforms and geomorphological processes has recently been favored by the use of geomorphometric techniques supported by the development of digital terrain analysis. In this context, the present study proposes a method for the identification of tops (convex and pointed), ridges and valleys segments (flat, open or closed) with parameters of three geomorphometric attributes derived from a Digital Terrain Model (DTM): contributing area (calculated by the D-Infinity method), Black Top Hat (BTH) and White Top Hat (WTH). The Top Hat calculation includes a regional neighborhood analysis of elevation values, with a function of opening (valley extraction by BTH) and closing (top extraction by WTH). The state of Paraná (Brazil) was adopted as the study area for the application of the proposal, due to the diversity of geomorphological contexts, using a DTM with spatial resolution of 20 meters and interpolated by the Topogrid method. The modeling considered an object-oriented classification, based on the definition of the features to be modeled (conceptual model) and the sample reference of occurrence of such objects in the landscape (heuristic model), thus defining the geomorphometric parameters for the representation. The landforms derived from the application of the proposal were consistent with both regional and local geomorphological characteristics, attested by fieldwork carried out throughout the state of Paraná. The global accuracy of the mapping was $94.4 \%$. We highlight the potential of the method presented as a support tool for geomorphological mapping studies, whose parameterization gives the possibility of methodological replication and decrease of subjectivity in the operational stages. It is also emphasized that the processing and quality of the digital terrain model directly affect the results and that the parameters can be adapted according to the objectives of the mapping and landscape configuration of the study area.
\end{abstract}

\section{INTRODUÇÃO}

O emprego de técnicas geomorfométricas, derivadas da modelagem digital do relevo, para o mapeamento de objetos geomorfológicos, tem se destacado como ferramenta metodológica para diversas finalidades (DRĂGUT e BLASCHKE, 2006; HENGL e REUTER, 2009; BISHOP et al., 2012; DEKAVALLA e ARGIALAS, 2017; PIPAUD e LEHMKUHL, 2017). Sobretudo nas últimas duas décadas, conforme Rigol-Sanchez et al. (2015), a geomorfometria - compreendida como a ciência da análise quantitativa da superfície terrestre (PIKE, 2000; WILSON e GALLANT, 2000) - teve significativo progresso devido à flexibilidade e rapidez para a realização de cálculos e mensurações com auxílio da análise computadorizada de modelos digitais do terreno (MDTs) e os respectivos cálculos de atributos geomorfométricos. 
Há uma importante diferenciação de análise, proposta por Evans (1972), que subdivide a geomorfometria em geral e específica. A geomorfometria geral enfatiza os parâmetros, ou seja, tem como enfoque a extração de medidas descritivas e trata a superfície de modo contínuo. A geomorfometria específica, por sua vez, prioriza a extração de feições do relevo, entendidas como objetos, e, portanto, contempla a discretização da superfície.

Um dos principais objetivos da geomorfometria é a extração de assinaturas para a representação de objetos geomorfológicos. No contexto atual da modelagem em ambiente informatizado, tais assinaturas são extraídas em diferentes escalas espaciais de MDTs e descrevem a complexidade das formas de relevo como a síntese dessas características verificadas individualmente (SCHMIDT e ANDREW, 2005). Em consonância à proposição de Pike (1988), uma assinatura geométrica define um conjunto de mensurações que possibilita descrever formas topográficas bem o suficiente para distinguir paisagens geomorfologicamente distintas.

Sobre a representação de objetos a partir de MDTs, Dragut e Eisank (2011) enfatizaram questões relacionadas à delimitação, classificação e regionalização como função de escala. Diversos autores apontaram a dependência de escala em MDTs e, consequentemente, de produtos derivados (GALLANT e HUTCHINSON, 1997; SCHMIDT e ANDREW, 2005; GROHMANN e SAWAKUCHI, 2013), o que denota o rigor metodológico que deve acompanhar as etapas da modelagem.

Segundo Bishop et al. (2012), a análise orientada a objeto pode ser uma solução para o mapeamento de distintas feições geomorfológicas. Nesse processo, inicialmente é necessário realizar a segmentação com base em critérios específicos para a determinação de entidades espaciais denominadas de objetos. Referente à organização de classificações de formas de relevo de modo automatizado, MacMillan e Shary (2009) apontaram cinco procedimentos principais: i) estabelecimento do(s) objeto(s) espacial(is) da classificação; ii) especificação e computação das variáveis de entrada; iii) extração ou criação de regras de classificação; iv) aplicação das regras de classificação e v) estimativa e avaliação da acurácia.

Dentre os objetos morfográficos mais usuais em mapeamentos geomorfológicos, as características dos topos e vales se destacam por indicarem padrões de dissecação, processos atuantes, efeitos da erosão diferencial e relações de energia. Nesse sentido, o presente trabalho objetivou a elaboração de um método para identificação de topos aguçados e convexos, segmentos de cristas e vales planos, abertos e fechados, a partir de atributos geomorfométricos, numa abordagem orientada a objeto apoiada na assinatura geométrica de cada feição, considerando sua ocorrência na paisagem por meio de controle de campo. Com a finalidade de verificar a aplicabilidade da proposta em distintos contextos geomorfológicos, a adoção do Paraná como área de estudo é justificada pela abrangência e variedade do relevo no estado.

Quanto às características geomorfológicas regionais da área de estudo (figura 1), destaca-se o trabalho pioneiro de Maack (1981), que na década de 1940 propôs a primeira regionalização geomorfológica do Paraná (Litoral, Serra do Mar, Primeiro, Segundo e Terceiro Planaltos Paranaenses); o mapa geomorfológico do Paraná, publicado por Santos et al. (2006) e Oka-Fiori et al. (2006), que foi o primeiro trabalho de cartografia geomorfológica sistemático realizado para todo o estado e identificou 50 subunidades morfoesculturais conforme o $3^{\circ}$ nível taxonômicos de Ross (1992); e, mais recentemente, estudos que aplicaram técnicas e classificações geomorfométricas semiautomatizadas para o mapeamento de formas do relevo no Paraná, como em Silveira e Silveira $(2015,2016$ e 2017) e Silveira et al. (2014; 2018).

A geologia do estado do Paraná é subdivida por Mineropar (2001) em dois grandes compartimentos macroestruturais: 1) o Escudo Paranaense, com as rochas magmáticas e metamórficas mais antigas do estado, entre o período Arqueano e Paleozoico, constituintes do embasamento da Plataforma Sul-Americana e parcialmente recobertas por sedimentos recentes de origem marinha e continental e 2) a Bacia do Paraná, com rochas sedimentares e vulcânicas que recobriram o Escudo entre o período Siluriano e Cretáceo, e cujo registro estratigráfico compreende um pacote sedimentar-magmático com espessura próxima a $7 \mathrm{~km}$, no qual o depocentro estrutural da sinéclise coincide com a região da calha do rio Paraná (MILANI et al., 2007). 


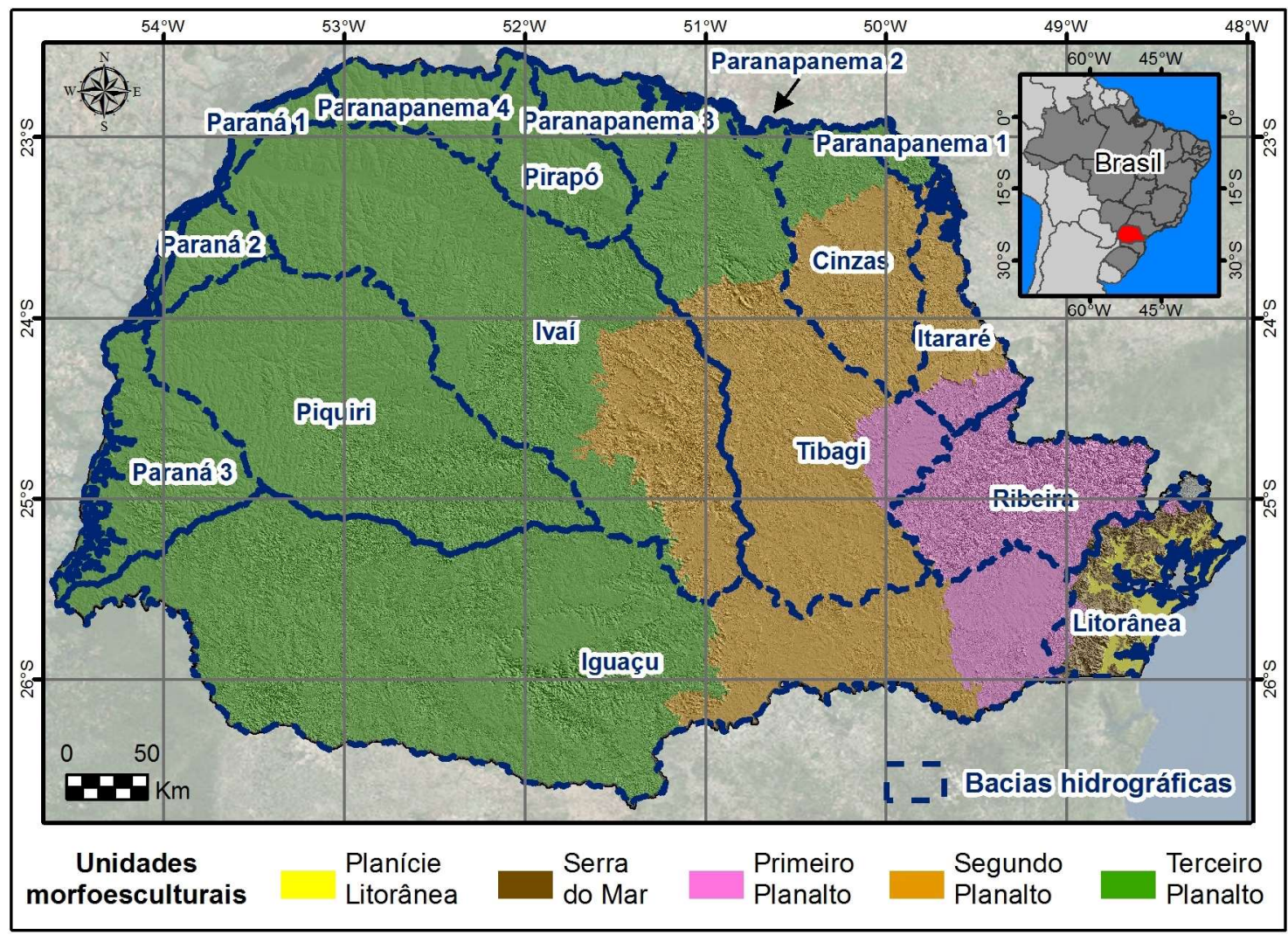

Figura 1 - Principais unidades morfoesculturais e bacias hidrográficas do estado do Paraná

\section{MATERIAIS E MÉTODOS}

\section{Processamento do MDT e dos atributos geomorfométricos}

A terminologia empregada de Modelo Digital do Terreno (MDT) segue a designação e compreensão em acordo com El-Sheimy et al. (2005), que se refere aos valores altimétricos do terreno desconsiderando quaisquer objetos sobre ele. Os valores são expressos em valores de metros de elevação acima do nível do mar em células de uma grade regular quadrangular.

O MDT foi obtido por meio de interpolação de um conjunto de dados vetoriais com uso do método Topogrid, (HUTCHINSON, 1988), processado no software ArcGIS 10.1 (ESRI, 2010). Foi necessária a fragmentação do MDT na etapa de processamento em oito partes, pois o tratamento da totalidade da área extrapolava a capacidade de processamento e limitação do número tamanho da grade disposta no software. Os dados vetoriais digitais de entrada foram: i) curvas de nível, que passaram por um processo de verificação de consistência dos valores das cotas, com correção de erros na tabela de atributos quando apresentavam valores díspares das curvas de subjacentes e adjacente e/ou quando com valor zero; ii) pontos cotados, que foram submetidos à verificação de consistência mediante os valores das curvas de nível imediatamente inferiores, para não resultarem em depressões, e também a verificação do valor igual a zero, que resultaria artificialmente em topos planos e na forma de platôs; c) rede hidrográfica, que passou por correção do sentido de fluxo do vetor, partindo de montante para jusante.

Os dados vetoriais foram extraídos das cartas topográficas do Departamento de Serviço Geográfico do Exército (DSG) e do Instituto Brasileiro de Geografia e Estatística (IBGE). Para a região leste do Paraná, que abrange a Planície Litorânea, Serra do Mar e porção leste do Primeiro Planalto estavam disponíveis 86 folhas na escala 1:25:000 e para o restante do estado 297 folhas na escala 1:50.000.

A resolução da grade do MDT adotada para a representação da área de estudo foi de $20 \mathrm{~m}$. A decisão desse valor se apoiou na mesma dimensão de equidistância entre as curvas de nível das cartas topográficas da escala 1:50.000, em função do número majoritário 


\section{Método Geomorfométrico para Mapeamento de Topos, Cristas e Vales}

de folhas disponível para a área, que levou a generalização das informações dispostas na escala 1:25.000, visto que na estrutura raster (matricial) adotado no MDT, a resolução da grade exerce direta influência de generalização em função da dimensão da célula. Essa mesma dimensão de célula foi adequada por Silveira e Silveira (2017), quando contemplado na sua avaliação as variáveis cartográficas e de complexidade do relevo no estado do Paraná.

A partir do MDT obtido foram derivados três atributos geomorfométricos primários e de cálculo regional, que serviram de base para a modelagem de topos, cristas e vales: Área de contribuição, Black Top Hat e White Top Hat.

A área de contribuição foi quantificada pelo método proposto por Tarboton (1997), com o algoritmo D-Infinito processado pelo software SAGA versão 2.2.2. Nesse método, inicialmente é determinado o ângulo de direção do fluxo (anti-horário a partir do leste) como a direção mais íngreme considerando as oito faces formadas em uma janela $3 \times 3$ células, diferindo do algoritmo $D-8$ por considerar a proporção de fluxo para cada célula.

Após indicação das direções, o fluxo acumulado é quantificado pela soma das células à montante, ou seja, pela contribuição acumulada do entorno mais elevado. Considera-se, portanto, que o fluxo de cada uma das células drena para algum de seus vizinhos, tendo esse valor somado ao seu. Por fim, a área de contribuição é obtida pela multiplicação da área de cada célula do MDT (neste caso, $400 \mathrm{~m}^{2}$ ) pelo valor do fluxo acumulado (figura 2).

\begin{tabular}{|c|c|c|c|c|c|c|c|c|c|c|c|c|c|c|c|c|c|c|c|}
\hline \multicolumn{5}{|c|}{$\begin{array}{l}\text { MDT (Altimetria) } \\
\text { (célula } 20 \mathrm{~m} \text { x 20m) }\end{array}$} & \multicolumn{5}{|c|}{$\begin{array}{l}\text { Direção de fluxo } \\
\text { (D-Infinito) }\end{array}$} & \multicolumn{5}{|c|}{$\begin{array}{l}\text { Fluxo acumulado } \\
\text { (proporção de células) }\end{array}$} & \multicolumn{5}{|c|}{$\begin{array}{c}\text { Area de } \\
\text { contribuição }\left(\mathrm{m}^{2}\right)\end{array}$} \\
\hline 334 & 332 & 329 & 326 & 322 & 5.5 & 5.5 & 5.4 & 5.3 & 5.2 & 1 & 1 & 1 & 1 & 1 & 400 & 400 & 400 & 400 & 400 \\
\hline 333 & 329 & 324 & 320 & 316 & 5.9 & 5.8 & 5.5 & 5.5 & 5.2 & 1 & 2.5 & 3.1 & 2.2 & 2.1 & 400 & $1007 \mid$ & 1221 & 861 & 851 \\
\hline 332 & 328 & 321 & 315 & 310 & 6.1 & 6.1 & 5.7 & 5.5 & 5.3 & 1 & 2.3 & 4.2 & 5.4 & 4 & 400 & 914 & 1693 & 2164 & 1589 \\
\hline 331 & 327 & 320 & 311 & 304 & 6.3 & 6.3 & 6.2 & 6 & 5.7 & 1 & 2.2 & 3.7 & 7.2 & 12.2 & 400 & 863 & 1492 & 2861 & 4886 \\
\hline 331 & 327 & 319 & 310 & 302 & 0 & 0 & 0 & 0 & 0 & 1 & 2 & 3.1 & 4.6 & 7.9 & 400 & 815 & 1247 & 1828 & 3176 \\
\hline
\end{tabular}

Figura 2 - Método D-Infinito para determinação da área de contribuição

Já o atributo geomorfométrico derivado do método da transformação Top Hat considerou a análise de vizinhança regional a partir do MDT para sua obtenção. Essa função, aplicada de modo pioneiro à análise digital do relevo por Rodriguez et al. (2002), pode ser dividida em duas: i) Black Top Hat (BTH), com uma função de abertura, que mensura a altimetria mínima da altimetria máxima; ii) White Top Hat (WTH), com uma função de fechamento, que mensura a altimetria máxima da altimetria mínima, ambas a partir de uma janela móvel quadrangular predefinida, conforme ilustra a figura 3A. Operacionalmente, a análise de vizinhança foi realizada pela ferramenta Focal Statistics no software ArcGIS 10.1, seguida da etapa de álgebra de mapas. Ressalta-se que devido à variação do tamanho da janela móvel empregada no cálculo, a função Top Hat é afetada diretamente pelo fator de escala.

Ao subtrair os valores do BTH $\left(Z_{\text {minmax }}\right)$ pelo MDT ( $Z_{0}$, célula a célula) se obtém a extração dos vales (equação 2), e ao subtrair o MDT pelo WTH ( $Z_{\text {minmáx }}$ se obtém a extração dos topos (equação 3), de acordo com a figura 3B. Para ambos ainda é possível definir um valor limiar de corte a fim de eliminar artefatos residuais ou destacar apenas os principais vales e topos, como aponta o último passo da figura $3 \mathrm{C}$.

$$
\begin{aligned}
& \operatorname{Vales}(B T H)=Z_{\text {mí nmáx }}-Z_{0} \quad \text { (equação 2) } \\
& \operatorname{Topos}(W T H)=Z_{0}-Z_{\text {máxmín }} \quad \text { (equação 3) }
\end{aligned}
$$

\section{Parâmetros de modelagem das feições geomorfológicas}

A parametrização dos topos, cristas e vales foi concebida de modo semiautomatizado, utilizando-se de uma classificação orientada a objeto. A partir da definição das feições a serem modeladas (modelo conceitual) e da referência amostral de ocorrência de tais objetos na paisagem (modelo heurístico, por reconhecimento de campo), 
buscou-se a atribuição de parâmetros geomorfométricos para a representação dos mesmos. Essa etapa foi amparada pelo conceito de assinatura geométrica de Pike (1988), que se configura como um conjunto de mensurações que possibilita descrever e individualizar formas topográficas de paisagens e contextos geomorfologicamente distintos.

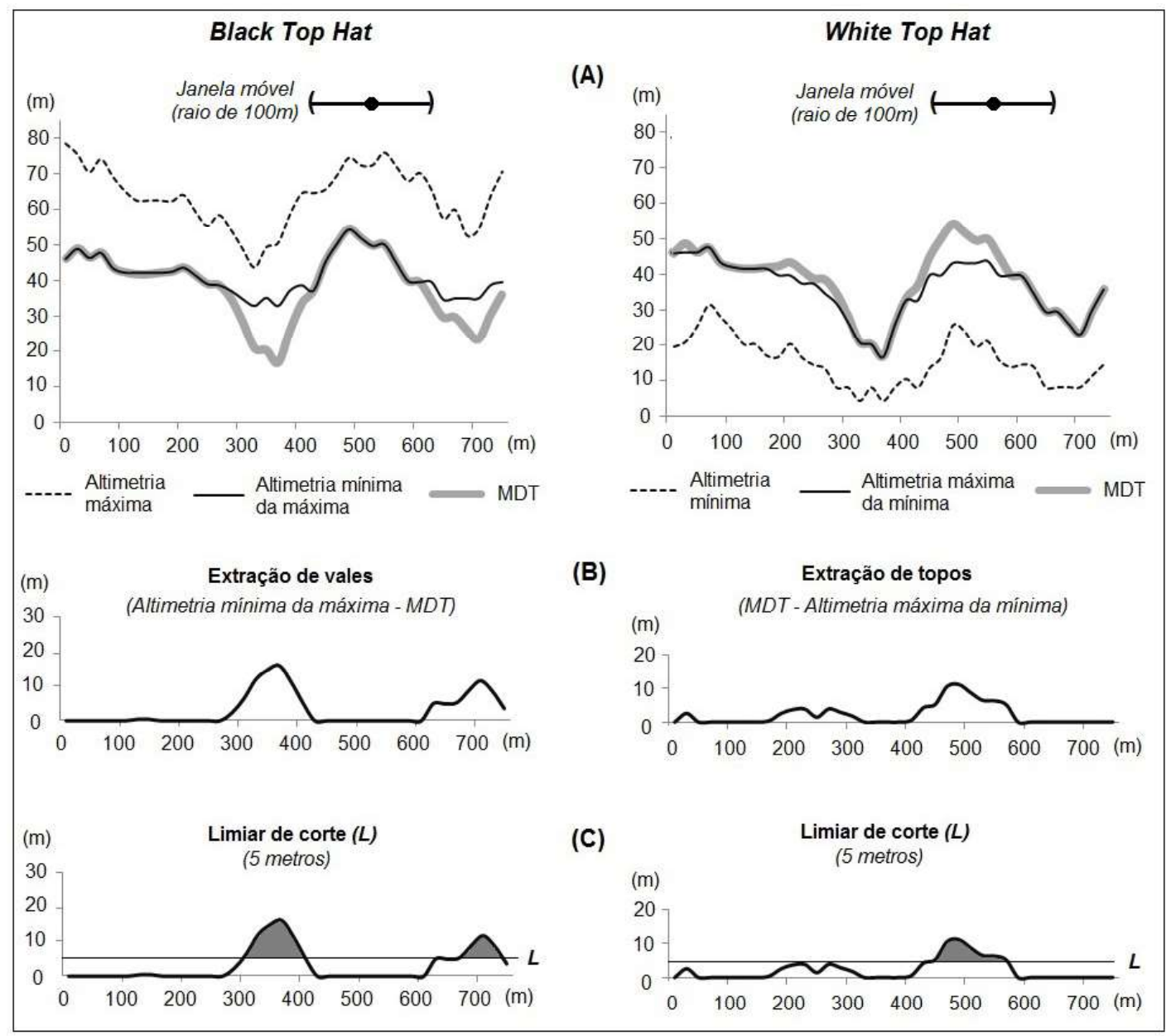

Figura 3 - Função Top Hat aplicada à análise digital do relevo

As regras de classificação são dispostas na tabela 1. Os vales planos, vales abertos e vales fechados foram modelados pela combinação entre área de contribuição, que marcou a ocorrência linear das feições, e BTH, que mensurou o nível de entalhamento dos vales em relação ao seu entorno (100m para cada margem). Com o cálculo inverso da transformação Top Hat, os topos, subdivididos entre topos convexos e interfluviais e topos aguçados, foram mapeados pelo WTH: quanto maior seu valor, mais pronunciado tende a ser o cume. As cristas, por sua vez, foram mapeadas como o traçado central do resultado obtido pelo WTH (ferramenta Thin, no software ArcGIS 10.1). A fim de destacar apenas as cristas contínuas, de maior expressividade, atribuiu-se o parâmetro de extensão mínima de $1 \mathrm{~km}$ para os segmentos lineares dessa feição.

O tamanho da janela móvel para cálculo do BTH e
WTH e o valor limítrofe da área de contribuição foram definidos considerando a proposta taxonômica de Dikau (1989), na qual optou-se pela categoria de Mesorelevo, com extensão entre $100 \mathrm{~m}$ e $10 \mathrm{~km}$ de largura, que atende, aproximadamente, a escala 1:50.000. Os critérios quantitativos adotados estão inseridos nesse intervalo, condizentes a uma escala geomorfológica predefinida.

Pelo fato da função Top Hat apresentar dependência escalar, os valores resultantes dos atributos BTH e WTH variam em função do tamanho da janela móvel. Por esse motivo, aplicou-se o critério estatístico de desvio padrão para a discretização e classificação dos objetos (referente ao limiar de corte, representado na figura 3C). O mesmo critério estatístico foi utilizado por Weiss (2001) e Silveira e Silveira $(2016$; 2017) no Índice de Posição Topográfica (IPT), outro atributo geomorfométrico de cálculo regional. 
Tabela 1: Parâmetros de classificação de vales, topos e cristas

\begin{tabular}{ccc}
\hline Morfologia & $\begin{array}{c}\text { Segmentação } \\
\text { Vales planos }\end{array}$ & Parâmetros \\
Vales & Vales abertos $>1 \mathrm{~km}^{2}$ e BTH (raio de $\left.100 \mathrm{~m}\right)<1$ desvio padrão \\
& Vales fechados & $\mathrm{AC}>1 \mathrm{~km}^{2}$ e BTH (raio de $\left.100 \mathrm{~m}\right)>1$ e $<3$ desvios padrões \\
& Topos convexos e $>1 \mathrm{~km}^{2}$ e BTH (raio de $\left.100 \mathrm{~m}\right)>3$ desvios padrões \\
Topos & interfluviais & WTH (raio de 100m) $>1$ desvio padrão \\
& Topos aguçados & WTH (raio de 100m) $>6$ desvios padrões \\
Cristas & - & WTH (raio de $100 \mathrm{~m})>2$ desvios padrões e extensão $>1 \mathrm{~km}$ \\
\hline
\end{tabular}

$\mathrm{Na}$ área de estudo, cada desvio padrão do WTH com raio de $100 \mathrm{~m}$ equivaleu a $3,3 \mathrm{~m}$, enquanto para o BTH o desvio padrão foi de $4 \mathrm{~m}$. O valor em metros, determinístico, pode ser relativo, daí a justificativa pelo uso do desvio padrão. Destaca-se, portanto, que a escolha dos parâmetros deve estar associada ao nível de detalhamento pretendido para o mapeamento.

\section{Etapas de conferência em campo}

Os trabalhos de campo compuseram parte essencial do mapeamento realizado. Num primeiro momento, findaram a observação in loco das feições geomorfológicas de interesse com a inferência preliminar dos parâmetros para cada objeto a ser modelado. Posteriormente, as campanhas de campo auxiliaram na verificação das classificações resultantes da modelagem - e, quando necessário, isso implicou na alteração dos parâmetros, seguido de novos produtos que passaram por nova conferência de campo.

Para a verificação em campo (figura 4) dos resultados obtidos, foram coletadas fotografias georreferenciadas em pontos representativos do relevo do estado do Paraná, obtidas no nível do solo e também em voos realizados com um drone, modelo DJI Phantom 3 professional. Além disso, foi realizado um acompanhamento em tempo real durante o deslocamento pelas estradas nas etapas de campo, utilizando-se de um GPS Garmin (modelo GPSmap 76CSx) acoplado a um netbook para a visualização dos resultados pelo software ArcGIS 10.1. Para esse procedimento, foi utilizada a extensão DNR Garmin.

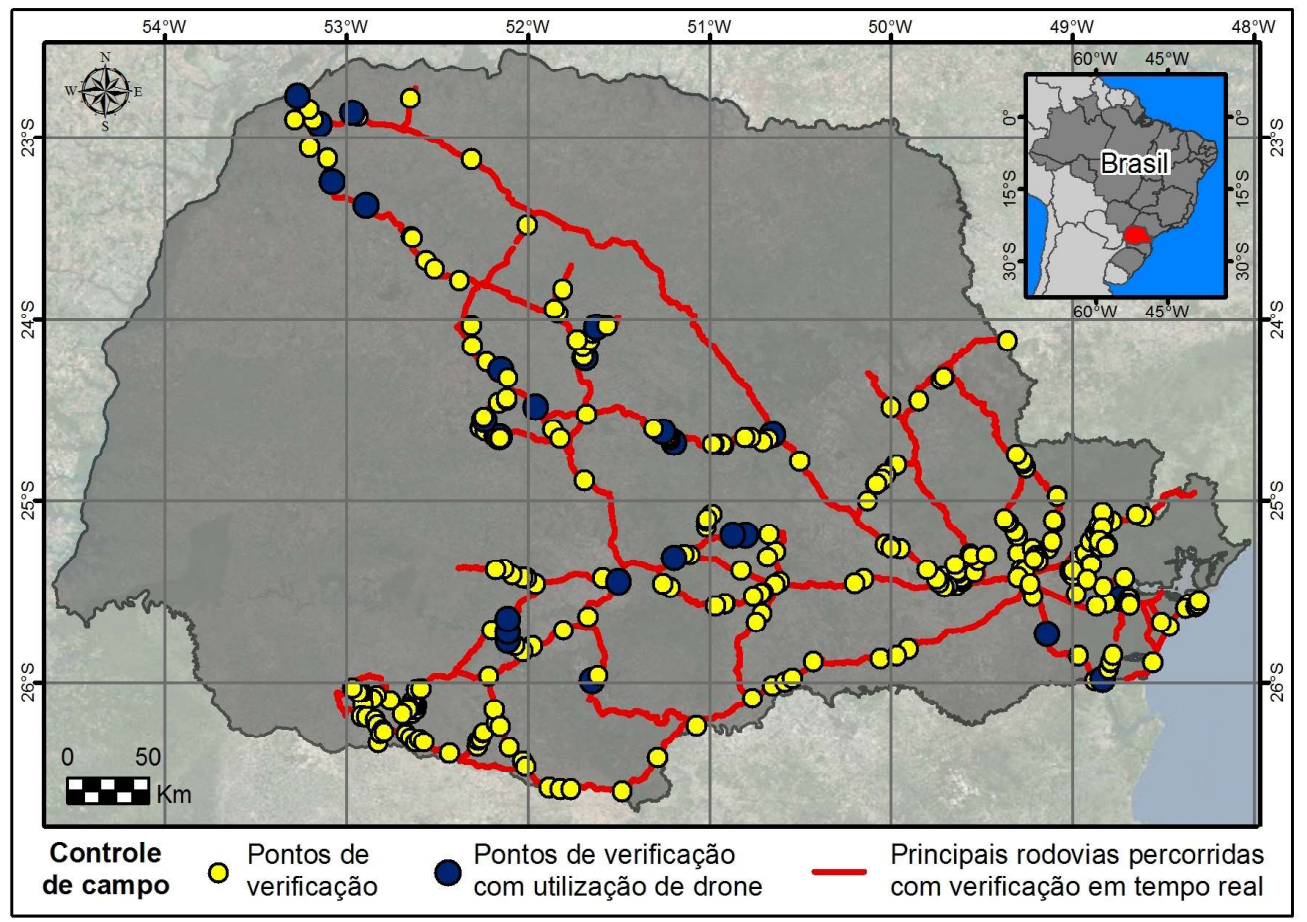

Figura 4 - Trabalhos de campo 
Ao todo foram 323 pontos de análise (com 25 voos de drone) e quase $5.000 \mathrm{~km}$ percorridos com acompanhamento em tempo real do mapeamento resultante no estado do Paraná, desconsiderando nesse cômputo a contabilização das estradas secundárias.

A avaliação quantitativa, por fim, foi realizada pela acurácia do mapeamento resultante, com os valores em porcentagem divididos em: i) exatidão global, que mensura as áreas ou limites concordantes entre as classes mapeadas e a representatividade na paisagem (equação 4); ii) erros de inclusão, que são as áreas ou limites superestimadas (equação 5); iii) erros de omissão, que se referem às áreas subestimadas pelo mapeamento (equação 6).

$$
E G=\frac{P C}{T P}
$$

(equação 4)

onde:

EG: exatidão global, que mensura a taxa de acerto da classificação;

PC: Pontos concordantes, que mediante a verificação de campo a classificação foi correta;

TP: Total de pontos de análise de campo.

$$
E O=\frac{P N C}{T P}
$$

(equação 5) onde:

EI: erros de inclusão, que são as áreas ou limites superestimadas;

PCI: Pontos classificação incorreta, feições que foram identificadas mas expressas em classes incorretas.

$$
E O=\frac{P N C}{T P}
$$

onde:

EO: Erro de Omissão, que se referem às áreas subestimadas;

PNC: Pontos não classificados, que as feições não foram contempladas na classificação.

\section{RESULTADOS}

Os resultados obtidos são apresentados, na sequência, seguindo a compartimentação geomorfológica do estado do Paraná (MAACK, 1981; SANTOS et al., 2006) em Planícies, Serra do Mar, Primeiro, Segundo e Terceiro Planaltos Paranaenses. De modo geral, as feições derivadas da aplicação da proposta foram condizentes tanto às características regionais do relevo, corroboradas por interpretações geomorfológicas mais abrangentes de trabalhos prévios, quanto às especificidades locais, atestadas pelos trabalhos de campo. As

\begin{tabular}{|c|c|c|c|c|c|c|c|}
\hline \multirow{3}{*}{ Feição geomorfológica } & \multicolumn{7}{|c|}{ Densidade $\left(\mathrm{m} / \mathrm{km}^{2}\right)$} \\
\hline & \multirow[b]{2}{*}{ Planícies } & \multirow{2}{*}{$\begin{array}{c}\text { Serra do } \\
\text { Mar }\end{array}$} & \multicolumn{2}{|c|}{ Primeiro Planalto } & \multirow{2}{*}{$\begin{array}{l}\text { Segundo } \\
\text { Planalto }\end{array}$} & \multirow{2}{*}{$\begin{array}{l}\text { Terceiro } \\
\text { Planalto }\end{array}$} & \multirow[b]{2}{*}{$\begin{array}{c}\text { Paraná } \\
\text { (área total) }\end{array}$} \\
\hline & & & $\begin{array}{c}\text { Porção } \\
\text { norte }\end{array}$ & $\begin{array}{c}\text { Porção } \\
\text { sul }\end{array}$ & & & \\
\hline Vales planos & 702 & 87 & 300 & 291 & 210 & 194 & 217 \\
\hline Vales abertos & 65 & 144 & 491 & 369 & 362 & 403 & 365 \\
\hline Vales fechados & 15 & 457 & 1565 & 232 & 305 & 175 & 234 \\
\hline Cristas & 18 & 950 & 1259 & 330 & 169 & 58 & 182 \\
\hline
\end{tabular}
quantificações gerais constam nas tabelas 2 e 3 .

Tabela 2: Densidade de segmentos lineares de vales e cristas

\begin{tabular}{|c|c|c|c|c|c|c|c|}
\hline \multirow{3}{*}{ Feição geomorfológica } & \multicolumn{7}{|c|}{ Proporção relativa de área ocupada $(\%)$} \\
\hline & \multirow[b]{2}{*}{ Planícies } & \multirow{2}{*}{$\begin{array}{c}\text { Serra do } \\
\text { Mar }\end{array}$} & \multicolumn{2}{|c|}{ Primeiro Planalto } & \multirow{2}{*}{$\begin{array}{l}\text { Segundo } \\
\text { Planalto }\end{array}$} & \multirow{2}{*}{$\begin{array}{l}\text { Terceiro } \\
\text { Planalto }\end{array}$} & \multirow{2}{*}{$\begin{array}{c}\text { Paraná } \\
\text { (área total) }\end{array}$} \\
\hline & & & $\begin{array}{c}\text { Porção } \\
\text { norte }\end{array}$ & $\begin{array}{c}\text { Porção } \\
\text { sul }\end{array}$ & & & \\
\hline Topos convexos e interfluviais & 1,8 & 24,2 & 27,9 & 21,5 & 12,8 & 6,4 & 9,7 \\
\hline Topos aguçados & 0,1 & 4,7 & 5,4 & 0,8 & 0,6 & 0,2 & 0,7 \\
\hline
\end{tabular}

Tabela 3: Proporção relativa de áreas mapeadas como topos 
Referente aos parâmetros destaca-se, inicialmente, que as regras de classificação unificadas para todo o estado do Paraná, com grande diversidade geomorfológica e, portanto, geomorfométrica, indicam valores médios, adequados à área de estudo em sua totalidade, cujo aprimoramento na delimitação dos objetos mapeados é possível pela adaptação dos parâmetros conforme demandas e especificidades de recortes locais. A proposta metodológica apresentada permitiu representar as feições denudacionais (topos e cristas) e fluviais (vales) com apenas três atributos geomorfométricos: área de contribuição, White Top Hat e Black Top Hat.

A avaliação quantitativa denotou a eficiência da proposta metodológica. Dos 323 pontos de conferência em campo, distribuídos em distintos contextos geomorfológicos da área de estudo, constatou-se que 305 tiveram o mapeamento correto das feições modeladas. Isso representou $94,4 \%$ de exatidão global.

Os 18 pontos com divergências (que representam $5,6 \%$ de erros da modelagem) podem ser subdivididos em 4 pontos que foram subestimados $(1,2 \%)$ e 14 pontos que foram superestimados $(4,4 \%)$. Os erros de subestimação foram caracterizados pela ausência de mapeamentos de vales (dois na Serra do Mar e outros dois na porção norte do Primeiro Planalto, ambas regiões muito dissecadas). Ressalta-se que esse é um erro que pode ser controlado pela definição dos parâmetros para a modelagem dos vales. Utilizou-se, no presente trabalho, um critério único para todo o estado do Paraná. Assim, ao diminuir o valor da área de contribuição, tais vales seriam identificados. Todavia, aumentaria o número de vales superestimados em outros contextos geomorfológicos.

Os erros de superestimação (14), por sua vez, contemplaram: segmentos de vales mapeados com classes distintas (6), sobretudo em áreas de transição entre vales fechados (V) e vales abertos (U), distribuídos em toda a área de estudo; segmentos de cristas com extensão superior à observada em campo (4); topos aguçados que, na realidade, são topos convexos (2); mesetas erroneamente mapeadas como topos convexos e interfluviais, na transição do Segundo para o Terceiro Planalto (2). Todos os erros de superestimação se atêm aos parâmetros escalares predefinidos, uma vez que o cálculo do BTH e WTH contemple análise de vizinhança e isso tenda a superestimar os limites dos objetos mapeados. Os erros de transição se referem à definição do valor de desvio padrão empregado nas discretizações. Salienta- -se, portanto, que se a parametrização dos atributos geomorfométricos for específica para as características geomorfológicas de recortes menores e homogêneos, tais erros tendem a diminuir.

Cabe destacar que segundo expresso por Hengl (2006) não existe uma única "melhor resolução" para calcular os parâmetros da superfície terrestre e para retratar e classificar o relevo. Assim, a resolução selecionada deve ser apropriada para representar e descrever as características de superfície de interesse para uma determinada aplicação, condicionada à base de dados, variação do relevo e objetivo a ser alcançado. Portanto, a adoção da resolução de $20 \mathrm{~m}$ para o MDT foi adequada, verificado por meio dos resultados aqui alcançados e corroborado pelo experimento de Silveira e Silveira (2017).

\section{Planícies}

Referente às planícies do Paraná, incluindo a litorânea, de gênese fluviomarinha, e as grandes planícies fluviais dos planaltos,com destaque para os rios Iguaçu, Tibagi, Ivaí e Paraná, nelas a baixa densidade de cristas (tabela 2) e baixa proporção relativa de área dos topos convexos e aguçados (tabela 3 ) reforçam a aplicabilidade do modelo em áreas planas. Pelo fato dos atributos geomorfométricos empregados serem calculados a partir da análise de vizinhança, não foi detectado a superestimativa das feições mapeadas, mesmo em áreas de transição, com porções mais declivosas. Entretanto, quanto maior o tamanho do raio de análise, mais pronunciado se mostrou o efeito de borda, especialmente nas zonas limítrofes das planícies.

Nesse compartimento, as poucas cristas mapeadas se vinculam aos morros isolados que estão próximos a Serra do Mar que, devido à escala do mapeamento geomorfológico do Paraná (SANTOS et al., 2006; OKA-FIORI et al. 2006), constam generalizados no polígono da planície fluviomarinha tido como referência. O mesmo ocorre para os topos convexos $(1,8 \%)$ e os pouco representativos topos aguçados $(0,1 \%)$.

Quanto aos vales, constatou-se o correto predomínio de feições planas, dez vezes superior às demais classes somadas. Os vales abertos e os vales fechados identificados nas planícies se localizam próximos às supracitadas áreas de transição, normalmente associadas às rupturas de declive com os terços médios das vertentes, como ilustra a figura 5, no contato com a 
região serrana. Dentre as planícies fluviais, a de maior densidade de vales abertos ou fechados foi registrada em União da Vitória, no rio Iguaçu, à montante da passagem do Segundo para o Terceiro Planalto Paranaense, onde o recuo erosivo do planalto basáltico derivou elevações residuais nas adjacências da feição agradacional.

\section{Serra do Mar}

A Serra do Mar, unidade geomorfológica com os principais contrastes geomorfológicos do estado, foi caracterizada, regionalmente, com predomínio de vales fechados, com grande proporção de topos mapeados (29\% da área total) e, consequentemente, de segmentos contínuos de cristas (quase $1 \mathrm{~km}$ a cada $\mathrm{km}^{2}$ ). Descrições apresentadas por Bigarella et al. (1978), Almeida e Carneiro (1988), Maack (1981), Costa et al. (2005), Santos et al. (2006) e Nascimento et al. (2013) salientaram tais características morfológicas, reforçando a gênese estrutural que condiciona a evolução do relevo serrano. $\mathrm{O}$ atlas geomorfológico do Paraná (OKA-FIORI et al., 2006) define a Serra do Mar com predomínio de "formas de relevo denudacionais, constituídas basicamente por escarpas e cristas com topos aguçados e topos convexos" (p. 12).

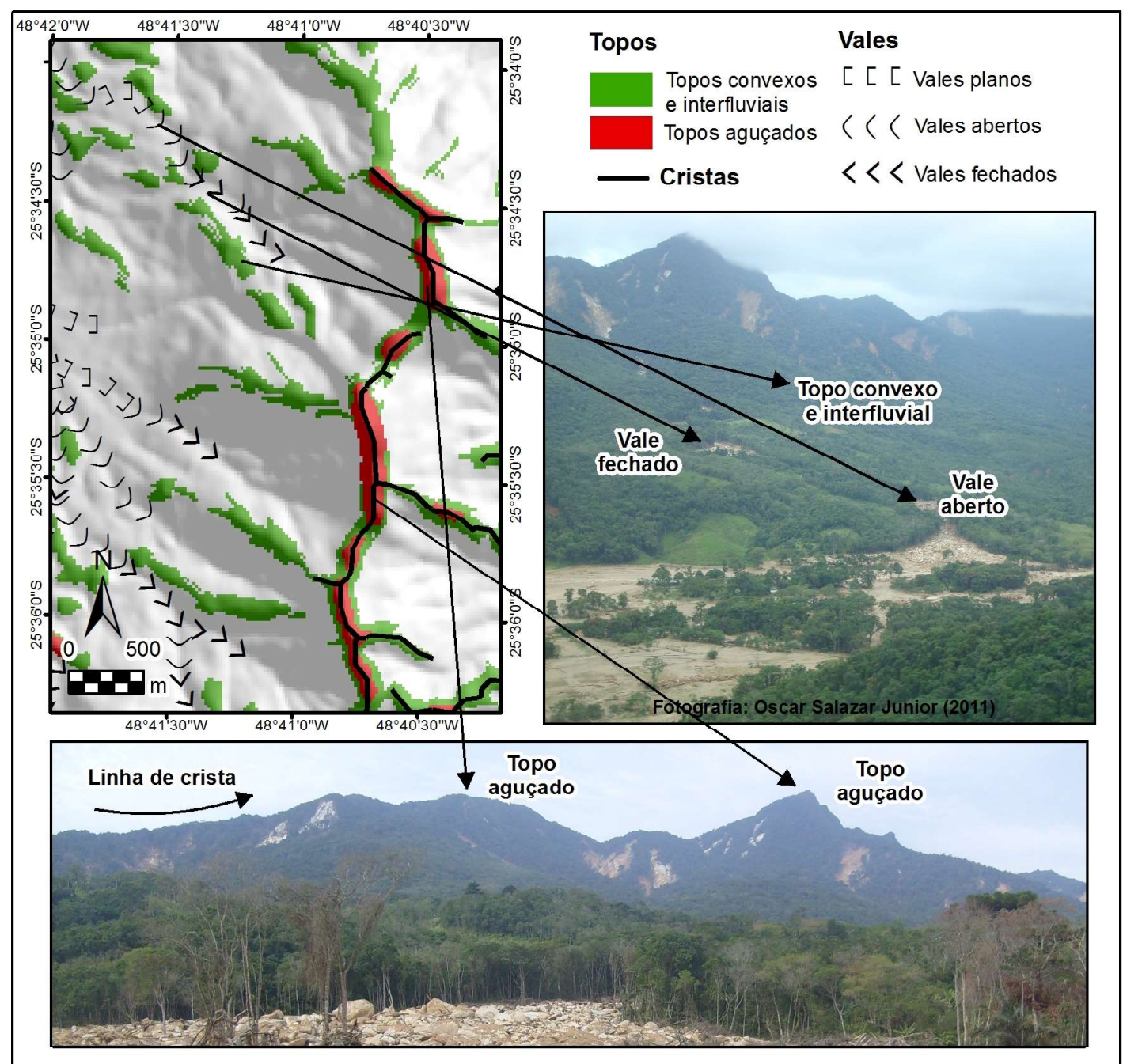

Figura 5 - Mapeamento na bacia hidrográfica do rio Jacareí, Serra da Prata

Localmente, a morfologia dos cumes se mostrou adequada à representação na paisagem. As principais elevações sustentadas por corpos graníticos, já bastante dissecadas, que conferem os altos topográficos e as linhas de cumeadas das serras locais, foram modeladas com topos aguçados e lineamentos contínuos de cristas destacadas. As porções adjacentes, sejam as ombreiras que intercalam núcleos expostos dos granitos ou os interflúvios secundários, notadamente nos terços médios das vertentes, foram associadas às feições convexas. 
Como exemplo, a figura 5 destaca a Serra da Prata, com quase $1500 \mathrm{~m}$ de altitude, no contato com a Planície Litorânea, que contém as características mencionadas dessa compartimentação. Os resultados foram semelhantes aos obtidos por Silveira e Silveira (2017), cuja compartimentação contemplou 10 formas de relevo.

Quanto aos vales, destaca-se que o limiar definido pela área de contribuição $\left(>1 \mathrm{~km}^{2}\right)$ limitou a ocorrência dessas feições aos canais de $2^{\mathrm{a}}$ e $3^{\mathrm{a}}$ ordem. Pelo fato da Serra do Mar apresentar drenagens encaixadas desde o terço superior das vertentes, para representá-las bastaria diminuir o valor estabelecido como parâmetro. Todavia, em contrapartida, porções da área de estudo com relevo menos dissecado teriam um detalhamento, no mapa, de vales pouco representativos na paisagem. Ou seja, por ser utilizado um parâmetro único para toda a área de estudo, o critério quantitativo buscou privilegiar um valor intermediário, que não detalhe tanto os vales em áreas de relevo suave e que, por outro lado, não faça a omissão de vales em áreas de relevo montanhoso.

Os vales fechados se relacionaram às incisões fluviais de grande ação erosiva, enquanto os vales abertos foram mapeados nas transições com quebra e redução de declividade, que expõem o rio a um novo equilíbrio na relação erosão e deposição. Na Serra do Ibitiraquire (figura 6), região que conta com as maiores elevações do sul do Brasil, culminando no Pico Paraná $(1877 \mathrm{~m}$ de altitude, figura 6C), os lineamentos estruturais (falhas normais NE-SW e enxames de diques na direção NW-SE, vinculados ao Arco de Ponta Grossa) condicionaram profundos vales encaixados com desníveis superiores a 600m e declividade média superior a $45^{\circ}$ (como na figura $6 \mathrm{C}$, que evidencia o Pico Ferraria). No mesmo recorte, a representação dos topos e das cristas correspondeu às feições observáveis.

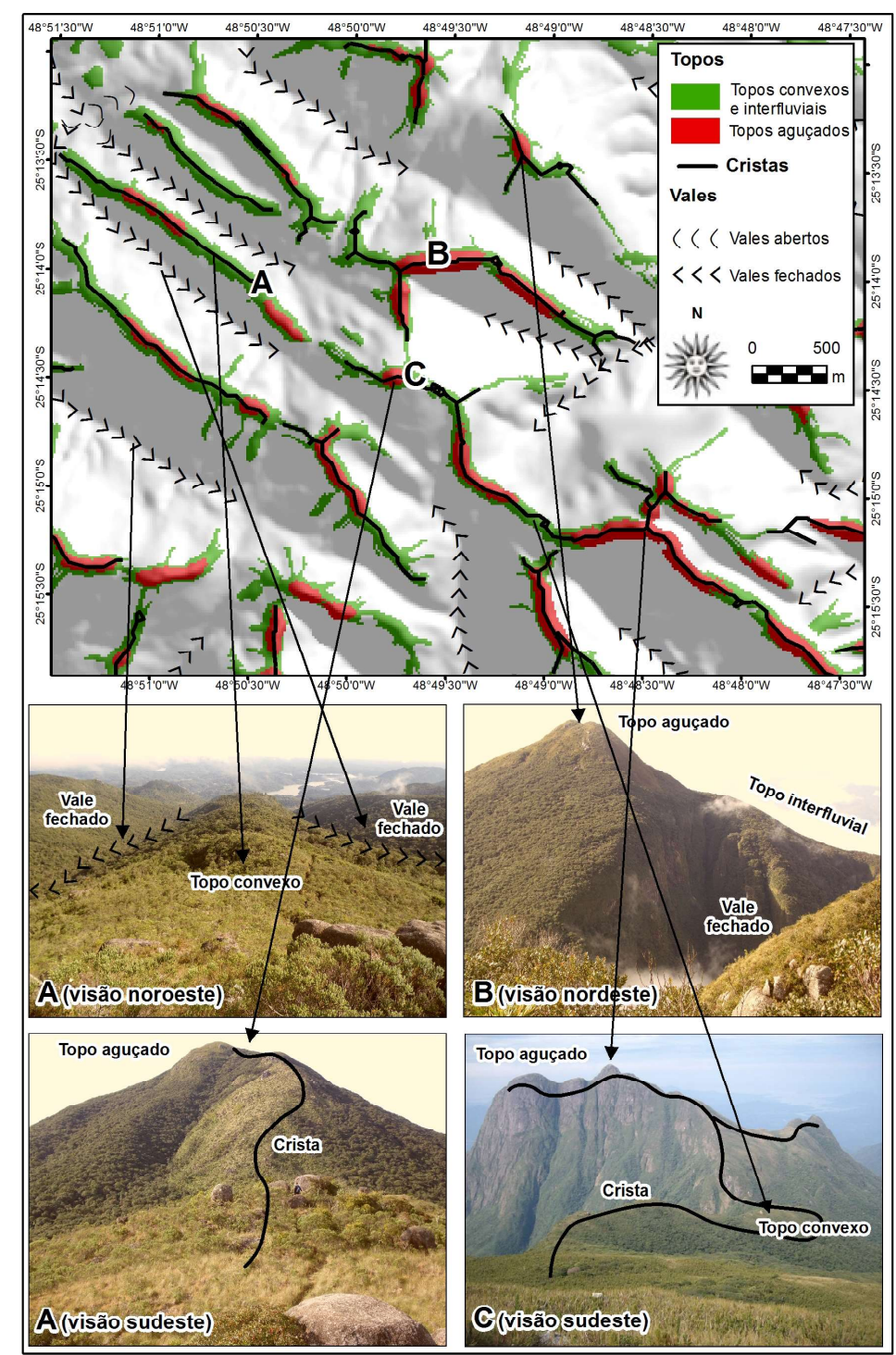

Figura 6 - Mapeamento na Serra do Ibitiraquire 


\section{Primeiro Planalto Paranaense}

No Primeiro Planalto os resultados denotaram significativas diferenças entre a porção norte e porção sul. Dois fatores principais explicam tais contrastes: a) a diversidade litológica e consequente erosão diferencial, já que essa é a unidade morfoescultural de maior complexidade geológica do estado e com grande diversidade litológica; b) o efeito do nível de base, pois a porção sul é abrangida pela bacia hidrográfica do rio Iguaçu, que drena para oeste e tem sua foz no rio Paraná, e a porção norte contempla a bacia hidrográfica do rio Ribeira, que drena para leste e deságua já no Oceano Atlântico. A relação entre extensão e altitude dos rios resulta numa curva hipsométrica mais acentuada no rio Ribeira do que no rio Iguaçu, o que reflete na dissecação do relevo.

Em aspectos morfológicos, a porção norte do Primeiro Planalto, condizente à bacia do rio Ribeira e que conta com relevo cárstico, teve resultados semelhantes aos obtidos na Serra do Mar, com predomínio de vales fechados, topos convexos e alta densidade de cristas, conforme exemplificado na figura 7, município de Cerro Azul. Em mapeamentos regionais, Maack (1981) denominou a área como "Região Montanhosa de Açungui" e o mapa geomorfológico do Projeto RADAMBRASIL (COSTA et al., 2005) a distinguiu como "Serrania do Ribeira", cujas atribuições qualitativas evidenciam as características de relevo dissecado.

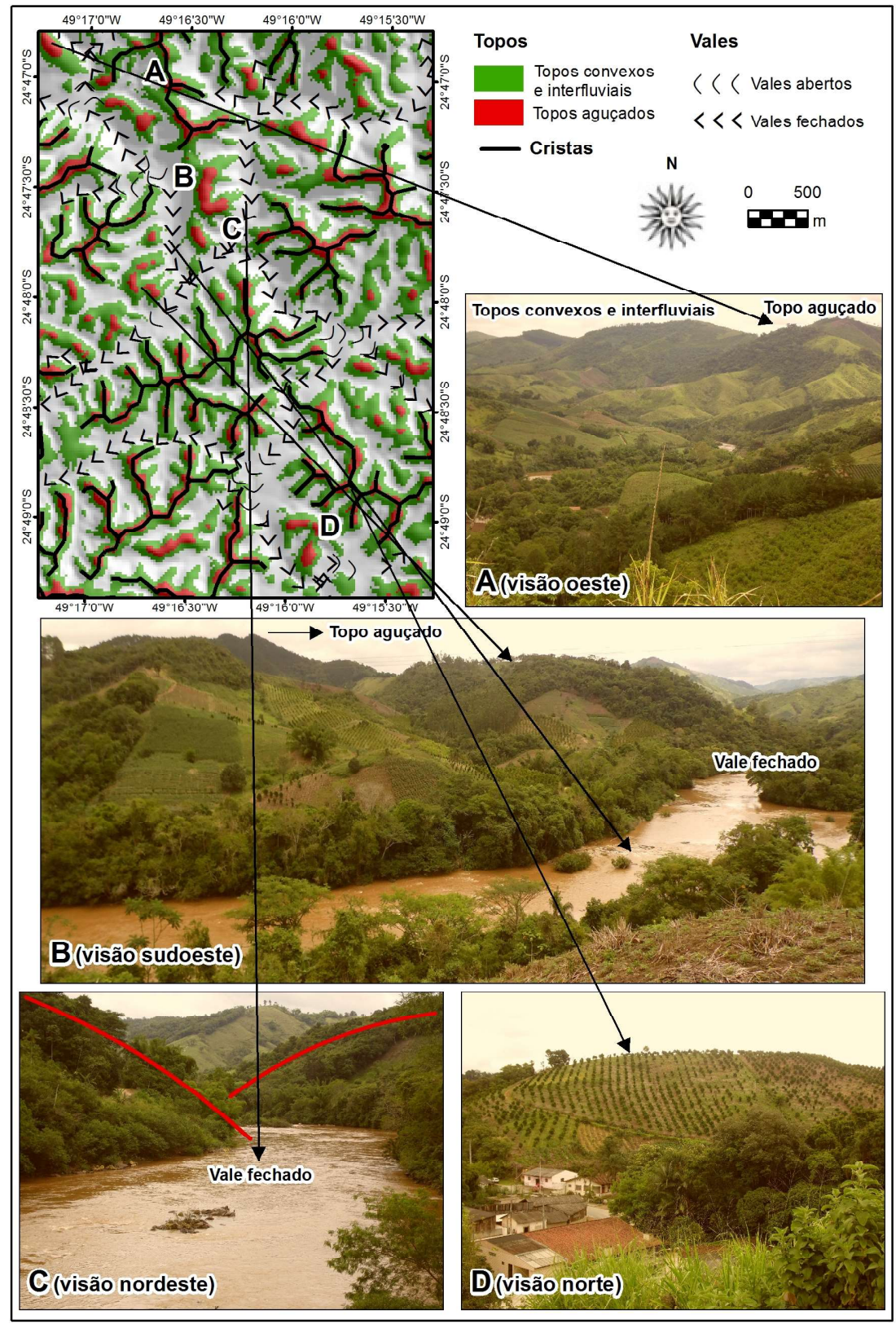

Figura 7 - Mapeamento porção norte do Primeiro Planalto 


\section{Método Geomorfométrico para Mapeamento de Topos, Cristas e Vales}

Apesar das semelhanças, o norte do Primeiro Planalto teve maior densidade de cristas e vales fechados do que a Serra do Mar, já que a área possui vertentes mais curtas e com menor amplitude altimétrica, na relação entre divisores e talvegues. Como consequência, um terço da área total foi mapeada como topos, sendo a maior do estado e seguindo a mesma proporção da Serra do Mar (tabela 3). Em relação aos vales, o método aplicado permitiu distinguir a morfologia dos segmentos transversais às linhas de drenagem de modo fidedigno.

A região de Castro, entretanto, localizada no noroeste do Primeiro Planalto - e no eixo central do Arco de Ponta Grossa - configura-se com um relevo que detém especificidades em função da litologia, com resquícios vulcânicos do supercontinente de Rodínia, conforme Mineropar (2001), e das bacias dos rios Tibagi e Itararé, que drenam a área para oeste (efeito do nível de base), conforme ilustrado pela figura 1 .

A modelagem derivada foi condizente à natureza geológica da região e aos efeitos da erosão diferencial na configuração do relevo local. Três padrões foram ressaltados: i) relevo bastante dissecado, com vales fechados, extensos segmentos de cristas e topos aguçados - sustentados pela Formação Itaiacoca, com corpos quartzíticos (normalmente orientados a nordeste) e diques (NW-SE); ii) relevo pouco dissecado, sobre o Complexo Granítico Cunhaporanga, que resultou no mapeamento de vales planos e restritos topos convexos; iii) relevo com diversidade de feições, inserido sobre uma associação vulcânica ácida, que apresentou maior equilíbrio na distribuição dos objetos mapeados.

A porção sul do Primeiro Planalto, por sua vez, drenada pela bacia do rio Iguaçu, apresentou características de relevo ondulado com valores contrastantes aos da porção norte. Os poucos topos aguçados, cristas e vales fechados mapeados estão associados, majoritariamente, aos blocos soerguidos de intrusões graníticas que afloram no interior do Primeiro Planalto. Na Bacia Sedimentar de Curitiba, que recobre rochas proterozoicas do Escudo Cristalino (MINEROPAR, 2001), constam extensas planícies holocênicas com predomínio de vales planos e sem ocorrência de cristas ou mesmo topos convexos significativos (Salamuni et al., 2013).

Nas demais áreas, constatou-se o predomínio de topos convexos com vales abertos e segmentos de vales planos nas planícies de inundação locais, sendo essa a paisagem predominante do sul do Primeiro Planalto, com relevo colinoso. A figura 8 ilustra tais feições, num recorte do município de São José dos Pinhais, compreendendo a formação do Complexo Gnáissico-Migmatítico que circunda a Bacia Sedimentar de Curitiba. Considerando a densidade dos vales, na relação entre extensão e área, os valores obtidos nesse compartimento são os que mais se aproximam da média calculada para todo o estado do Paraná (tabela 2).

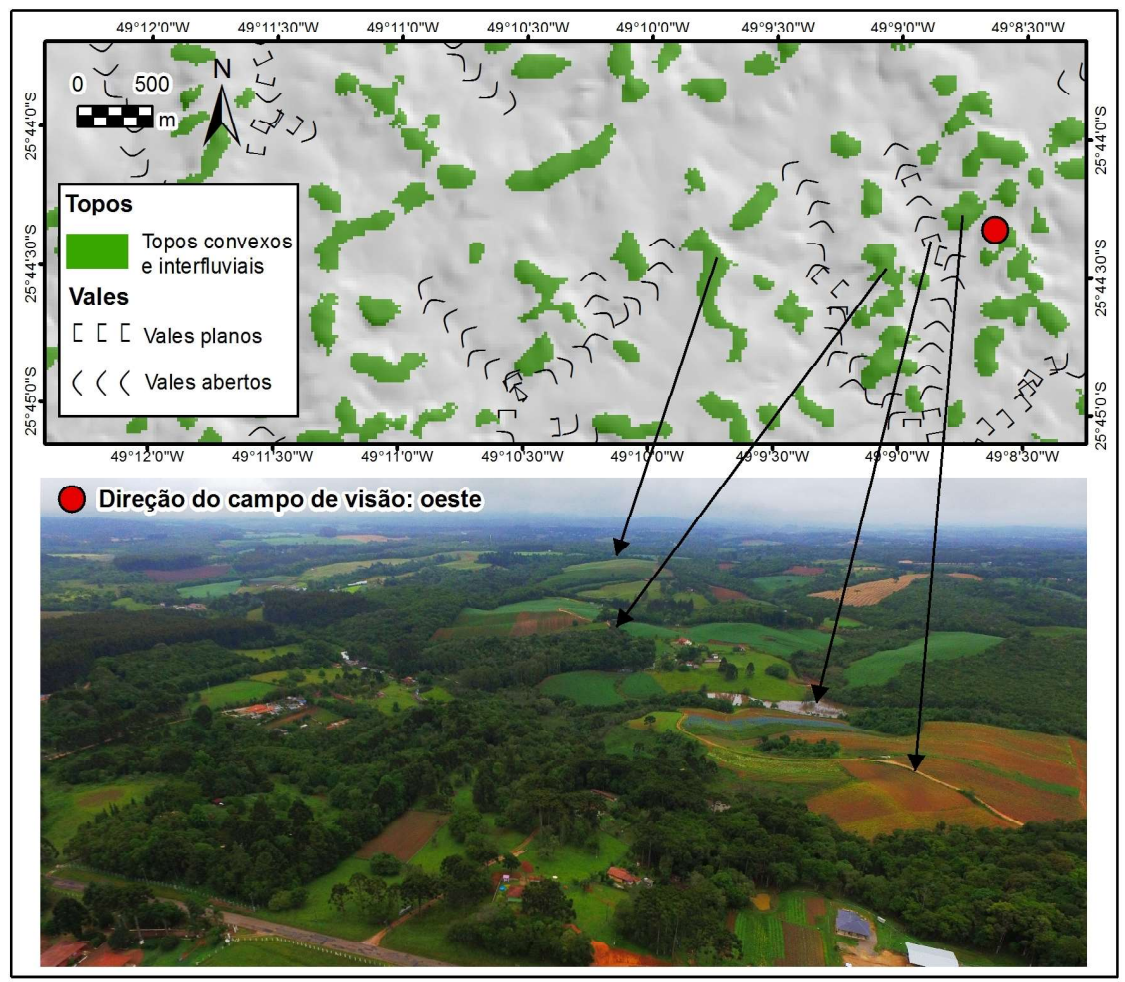

Figura 8 - Mapeamento na porção sul do Primeiro Planalto 


\section{Segundo Planalto}

Já no Segundo Planalto Paranaense, que abarca as rochas sedimentares paleozoicas da Bacia Sedimentar do Paraná, o mapeamento ressaltou as feições características de cada unidade litoestratigráfica associada às estruturas geológicas que condicionam a evolução do relevo. Em função dessa diversidade, destacou-se um relativo equilíbrio na densidade entre os tipos de vales mapeados (tabela 2).

As principais diferenciações geomórficas estão vinculadas aos seguintes Grupos do mapa geológico do Paraná, publicado pela Mineropar (2001): Grupo Paraná (Devoniano), Grupo Itararé (Carbonífero-Permiano Inferior), Grupo Guatá (Permiano Médio) e Grupo Passa Dois (Permiano Superior), além das estruturas vinculadas às rochas intrusivas básicas (Cretáceo). Cada
Grupo, com suas especificidades sobre o ambiente deposicional que originou as camadas sedimentares, influiu na configuração e evolução do relevo na bacia e, como consequência, tais aspectos geomorfológicos foram corroborados pelos tipos de topos e vales modelados.

A tabela 4 evidencia os resultados da quantificação para cada grande Grupo Geológico do Segundo Planalto. Destaca-se que, apesar do padrão de relevo ondulado, com predomínio de vales abertos, quanto menor a resistência erosiva do acamamento sedimentar, maior foi a proporção de cristas e topos mapeados. A delimitação das feições pela modelagem foi condizente às observações de campo e também a outros trabalhos prévios de mapeamento morfológico da área, tal como a publicação de Silveira e Silveira (2017).

Tabela 4: Densidade de segmentos lineares de vales e cristas e proporção relativa de áreas mapeadas como topos para cada Grupo Geológico do Segundo Planalto

\begin{tabular}{|c|c|c|c|c|c|}
\hline \multirow[b]{2}{*}{ Objetos geomorfológicos } & \multicolumn{2}{|c|}{ Grupo Paraná } & \multirow[b]{2}{*}{$\begin{array}{l}\text { Grupo } \\
\text { Itararé }\end{array}$} & \multirow[b]{2}{*}{$\begin{array}{l}\text { Grupo } \\
\text { Guatá }\end{array}$} & \multirow[b]{2}{*}{$\begin{array}{c}\text { Grupo } \\
\text { Passa Dois }\end{array}$} \\
\hline & $\begin{array}{c}\text { Formação } \\
\text { Furnas }\end{array}$ & $\begin{array}{c}\text { Formação } \\
\text { Ponta } \\
\text { Grossa }\end{array}$ & & & \\
\hline Vales planos $\left(\mathrm{m} / \mathrm{km}^{2}\right)$ & 140 & 170 & 150 & 240 & 260 \\
\hline Vales abertos $\left(\mathrm{m} / \mathrm{km}^{2}\right)$ & 480 & 280 & 380 & 360 & 330 \\
\hline Vales fechados $\left(\mathrm{m} / \mathrm{km}^{2}\right)$ & 330 & 180 & 300 & 160 & 350 \\
\hline Cristas $\left(\mathrm{m} / \mathrm{km}^{2}\right)$ & 15,9 & 9,4 & 57,7 & 49,2 & 361,8 \\
\hline Topos convexos ( $\%$ relativa $)$ & 3,4 & 3 & 9,1 & 7,7 & 14,3 \\
\hline Topos aguçados (\% relativa) & 0,06 & 0,02 & 0,1 & 0,12 & 0,93 \\
\hline
\end{tabular}

No Grupo Paraná, a Formação Furnas, cujo arenito possui origem aluvial e litorânea, é muito resistente à erosão devido à cimentação do mineral caulinita, o que explica a ínfima proporção de topos e cristas mapeadas. Nessa porção, que marca o reverso da escarpa da bacia sedimentar, predominam topos planos, associados aos remanescentes da paleosuperfície de idade eocênica-oligocênica (BIGARELLA et al., 1965). Por outro lado, nessa área foi constatada uma alta densidade de vales fechados, justificados pela erosão diferencial com os diques de diabásio (menos resistentes) que resultam em feições fluviais dissecadas, incluindo cânions. A Formação Ponta Grossa, também do Grupo Paraná, originada por depósitos litorâneos e de plataforma (MINEROPAR, 2001), teve resultados semelhantes.

Sob o Grupo Itararé, o mapeamento ressaltou o predomínio de vales abertos, já que o entalhamento fluvial segue a suavidade das colinas. A declividade média resultante na porção foi de $13,4 \%$, apenas $1 \%$ a mais do que na Formação Furnas. Por outro lado, a porcentagem relativa de área ocupada por topos convexos foi três vezes maior. Esse padrão indica que os divisores de água passam a ter maior convexidade por causa do aumento na densidade de drenagem.

Por ser uma extensa unidade geológica (por si só, quatro vezes maior do que a Serra do Mar), os resultados quantificados, gerais, não demonstram as variações existentes dentro do próprio Grupo. Como consta na tabela 4 , a principal diferença se refere ao aumento na densidade de drenagem e das feições decorrentes (vales), ainda que predomine o relevo colinoso, atestado pelo mapeamento com alta densidade dos topos aguçados. A figura 9 retrata tais características, onde a própria vegetação ripária auxilia na visualização dos vales. 


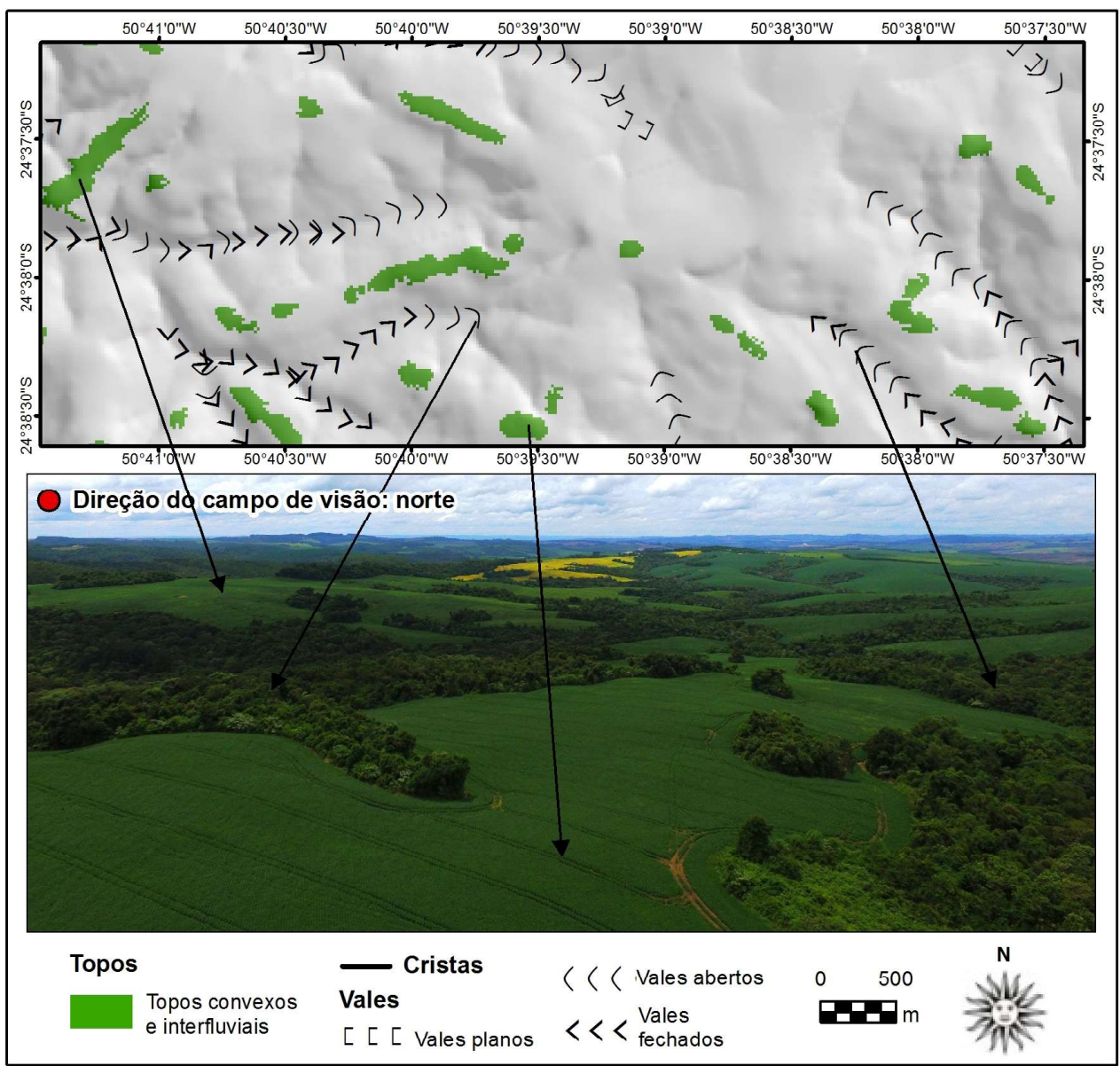

Figura 9 - Mapeamento na região de Ponta Grossa, Segundo Planalto

No Grupo Guatá (Perminiano Médio), com as Formações Palermo e Rio Bonito, depositados em ambiente litorâneo e de plataforma (MINEROPAR, 2001), as principais diferenças quantitativas do mapeamento em relação às demais unidades geológicas do Segundo Planalto (tabela 4) se referem à menor densidade de vales fechados.

Observou-se que quanto mais a oeste e quanto mais próximo do eixo central do Arco de Ponta Grossa, mais significativa é a influência das rochas intrusivas básicas que se sobrepõem às formações sedimentares, na paisagem, como altos topográficos. Se na borda leste da bacia sedimentar a erosão diferencial expôs vales encaixados, todos devidamente modelados, no rebordo oeste tais intrusões magmáticas caracterizaram topos alinhados, normalmente aguçados e no sentido NW-SE (no caso dos diques e soleiras de diabásio). A figura 10 exemplifica os resultados da modelagem numa porção com os efeitos marcantes da erosão diferencial.

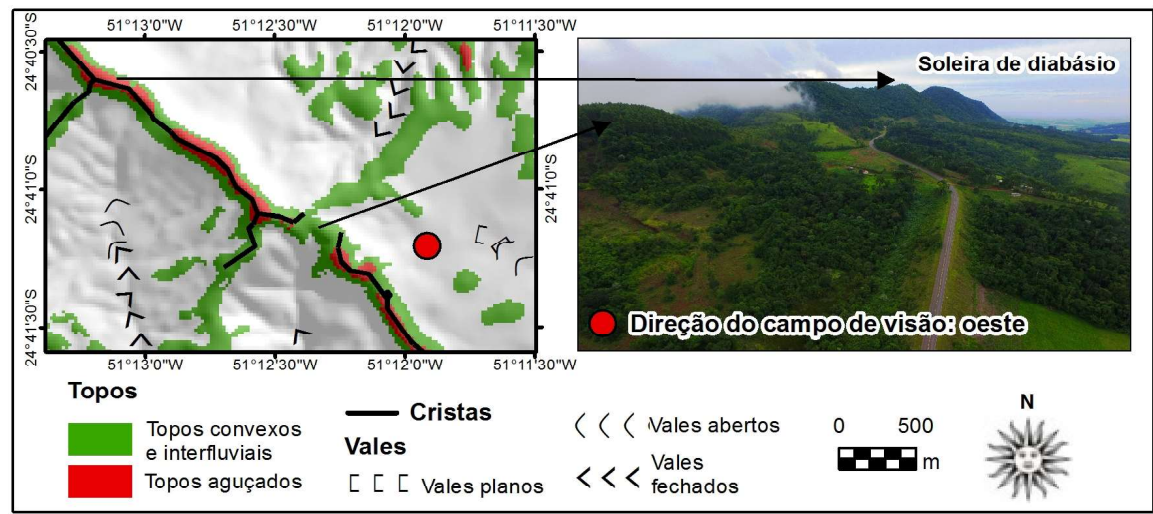

Figura 10 - Mapeamento na porção central do Segundo Planalto 
No Segundo Planalto, o último ciclo deposicional vinculado às oscilações transgressivo-regressivas do nível relativo do mar (MILANI et al., 2007), no Permiano Superior, compreende o Grupo Passa Dois do mapa geológico do estado do Paraná (MINEROPAR, 2001). Nessa porção da bacia, em contraste com a relativa monotonia do restante do Segundo Planalto, há uma diversidade maior de feições geomorfológicas. Os resultados quantificados, expressos pela tabela 4, reforçam tais características do mapeamento.

O conjunto dos resultados, com as variações acima da média geral, evidenciou o relevo mais dissecado que se observa na paisagem do Segundo Planalto. A propor- ção de cristas, por exemplo, foi 38 vezes superior ao mapeado na Formação Ponta Grossa. Como citado anteriormente, isso se deve, sobretudo, ao enxame paralelo de diques de diabásio que afloram na região. Destaca-se que as soleiras de diabásio não entraram nos cálculos, já que constam como unidades individualizadas no mapa geológico do Paraná.

Já próximo dos derrames basálticos que marcam o início do Terceiro Planalto, o contato vulcano-sedimentar resultou em feições proeminentes e entalhadas (em função do controle litológico), com predomínio de vales fechados e topos aguçados em morros testemunhos do recuo erosivo da escarpa basáltica (figura 11).

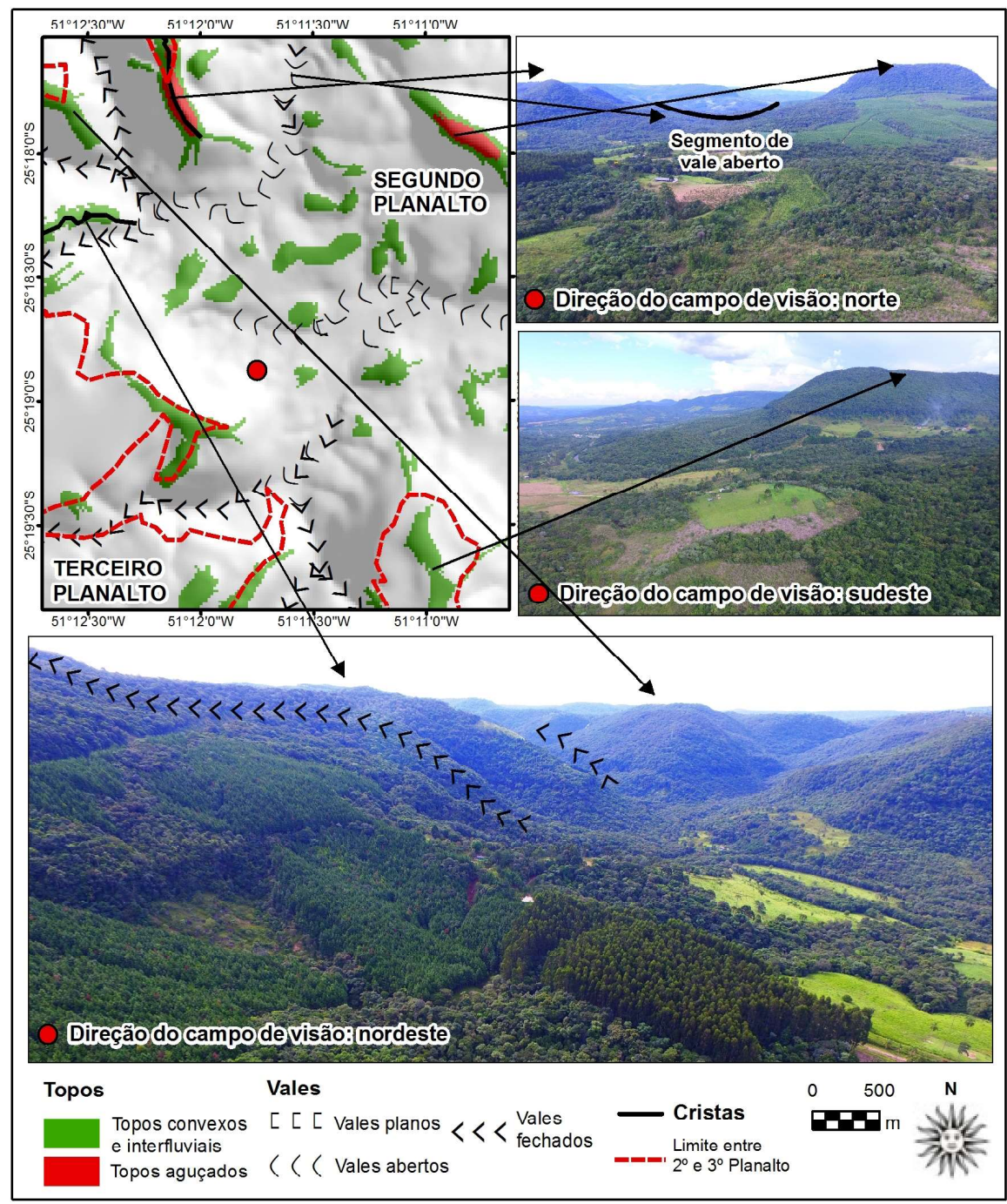

Figura 11 - Mapeamento na Serra da Esperança, transição entre Segundo e Terceiro Planalto

\section{Terceiro Planalto}

O mapeamento de topos e vales no Terceiro Planalto foi coerente à influência ocasionada no relevo pelos derrames basálticos mesozoicos, que constituem a Formação Serra Geral, e à cobertura sedimentar arenosa (depositada em ambiente árido no final do Cretáceo) 
correspondente ao Grupo Bauru na porção noroeste do estado do Paraná. Ainda que $77 \%$ do Terceiro Planalto (50\% do estado do Paraná) seja recoberto pela Formação Serra Geral, com predominância de basaltos (MINEROPAR, 2001), tal evento vulcânico possui fases e particularidades que tornam seu arranjo bastante heterogêneo: características das erupções hidrovulcânicas e dos eventos explosivos em centros eruptivos, depósitos de quedas das cinzas vulcânicas, interdigitação de produtos (como derrames, vulcanoclastos e piroclastos) e a própria sucessão dos depósitos vulcanoclásticos.

Conforme a quantificação realizada (tabelas 2 e 3 ) destaca-se o predomínio de vales abertos, a baixa densidade de cristas (com valores muito inferiores a todos os outros grandes compartimentos geomorfológicos do Paraná) e a baixa proporção relativa de área ocupada por topos. Conjuntamente, os resultados atestam o padrão de relevo colinoso do Terceiro Planalto, sobretudo na porção centro-norte. A porção centro-sul, por sua vez, apresentou-se mais dissecada e, portanto, foi onde a modelagem identificou a maior densidade de feições.

No âmbito geral, os principais topos mapeados podem ser vinculados aos depósitos vulcanoclásticos, que por serem mais resistentes formam altos topográficos. Entretanto, nem sempre essas feições são aguçadas. Nos divisores da bacia hidrográfica do rio Piquiri, por exemplo, cuja localidade está somente a $1700 \mathrm{~m}$ de distância dos divisores da bacia do rio Ivaí, os topos possuem forma predominante tabular, constituindo mesetas. $\mathrm{Na}$ modelagem, algumas mesetas foram mapeadas como "topos convexos e interfluviais", apesar da sua forma tabular, como destacado na figura 12. A representação das curvas de nível permite observar o aspecto plano dos topos mencionados, o que constitui um erro da modelagem (nesse caso, a inclusão da declividade como variável adicional poderia refinar o mapeamento). E conforme a erosão avança lateralmente, os topos resistentes ficam tão estreitos que formam segmentos de cristas.

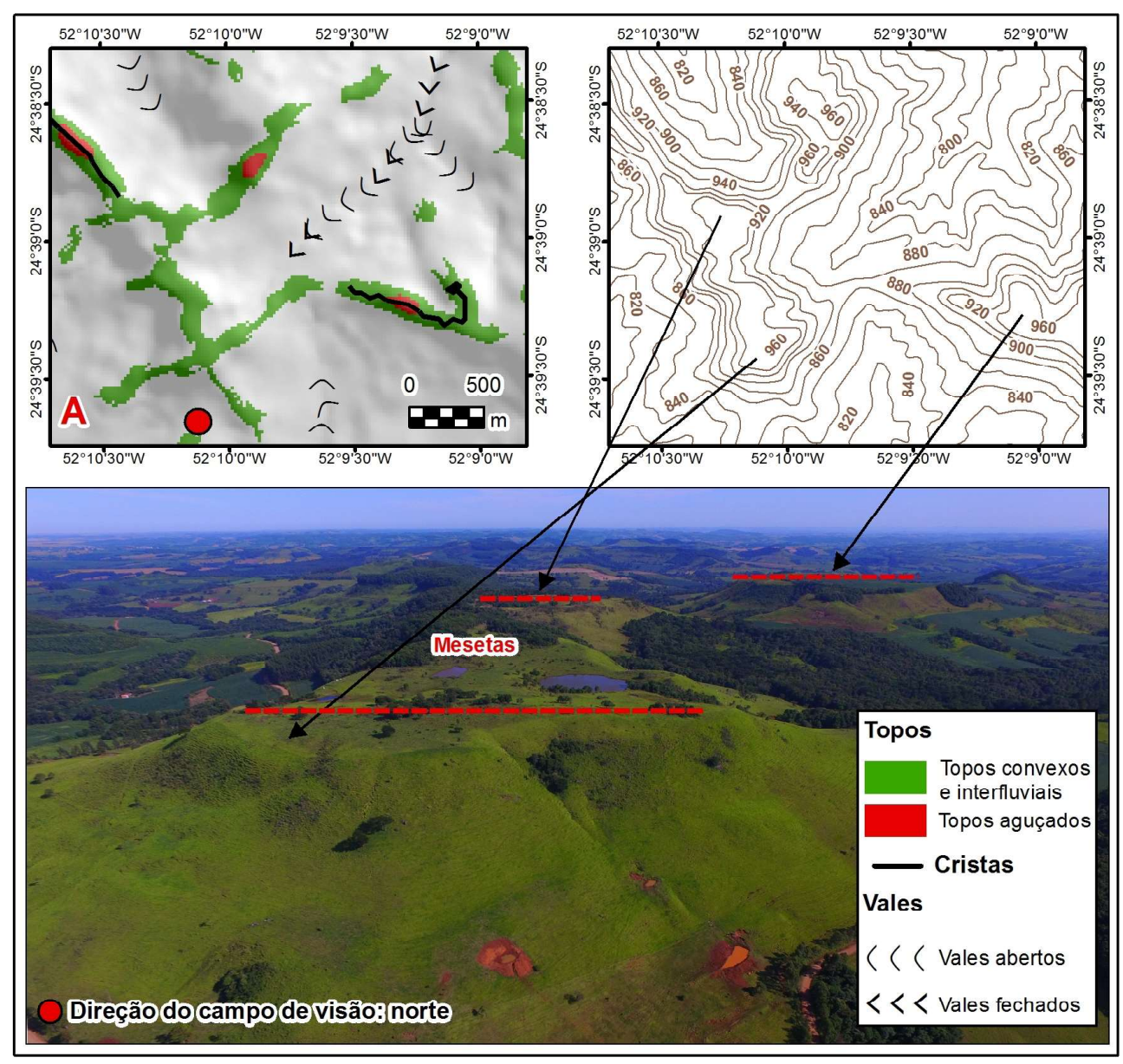

Figura 12 - Mesetas erroneamente mapeadas como topos convexos ou aguçados 
Observou-se, também, que a setorização das bacias hidrográficas do Terceiro Planalto tem relação direta com as características dos topos e vales. A conferência de campo num perfil longitudinal da bacia do rio Ivaí evidenciou as diferenças do relevo, amparadas por relações de energia em cada porção (divisores, terço médio, terço inferior e fundo de vale), e as consequentes feições identificadas pela modelagem. Apesar de algumas especificidades locais, verificou-se que quanto mais próximo do nível de base regional a convexidade dos topos e o entalhamento dos vales diminuem.

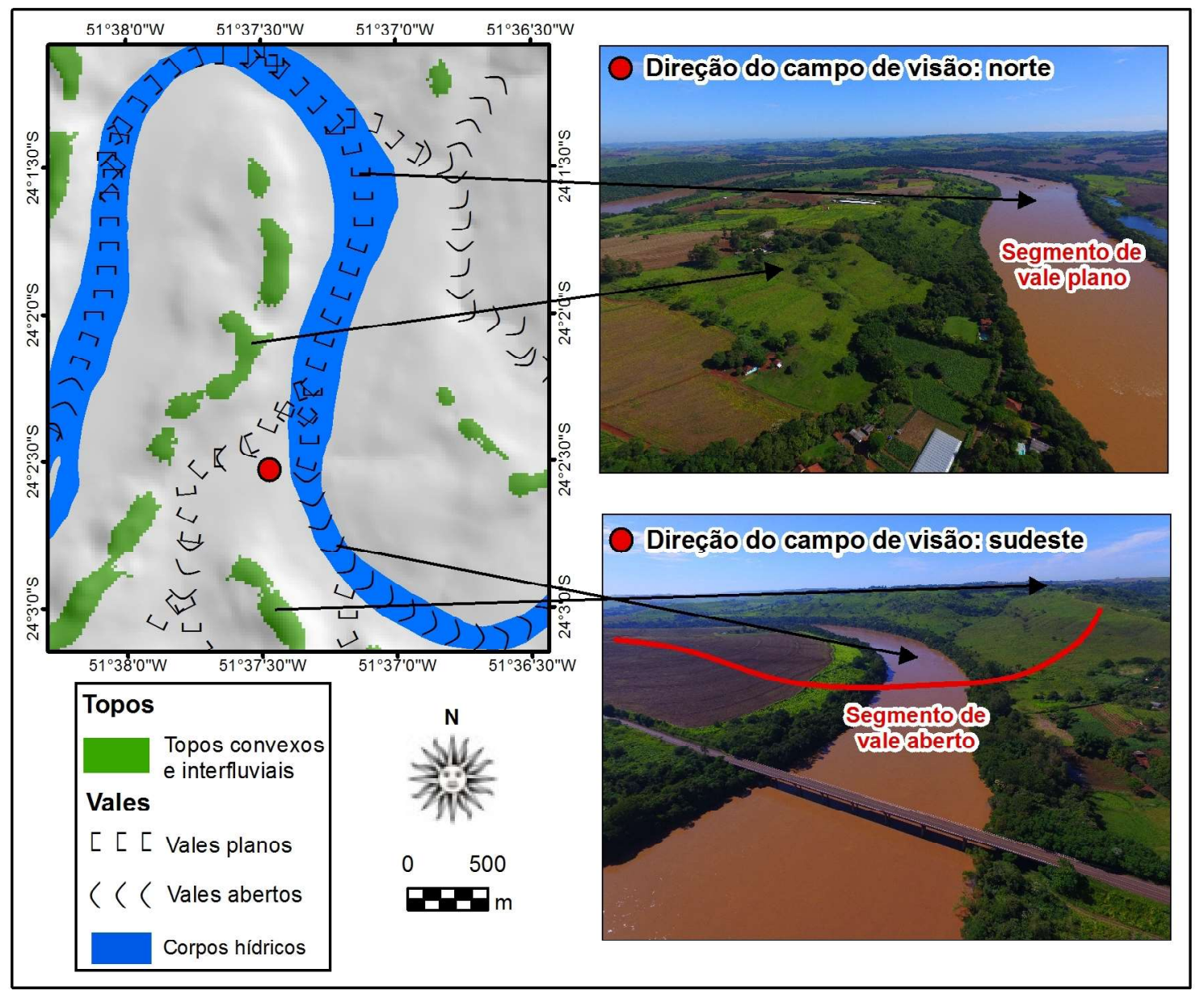

Figura 13 - Mapeamento no rio Ivaí, município de Borrazópolis

Às margens do rio Ivaí, como exposto pela figura 13, na região de Borrazópolis, a modelagem dos vales foi tão eficiente que conseguiu distinguir a transição exata entre os segmentos de vales planos dos vales abertos, sustentados por pequenas elevações no entorno, como ilustra a fotografia. Os topos convexos e interfluviais, nesse exemplo, evidenciam a paisagem típica da região.

Na região noroeste do Terceiro Planalto, devido à suavidade e extensão das vertentes, houve predomínio de vales abertos e planos e topos convexos e interfluviais. Dentre as paisagens de exceção, o município de
Terra Rica conta com feições peculiares derivadas de arenitos silicificados de depósitos arenosos do antigo Deserto Caiuá, que resultaram em elevações residuais conhecidas localmente como "Três Morrinhos". A figura 14 apresenta os resultados do mapeamento nessa porção. Em contraste ao relevo suave ondulado do entorno, com muitos vales planos e terraços (cujas feições fluviais são atestadas pela vegetação ripária), cada um dos três topos proeminentes foi corretamente modelado com topo aguçado, intercalados com topos convexos - e o conjunto total foi contemplado por um segmento de crista com $1,7 \mathrm{~km}$. 


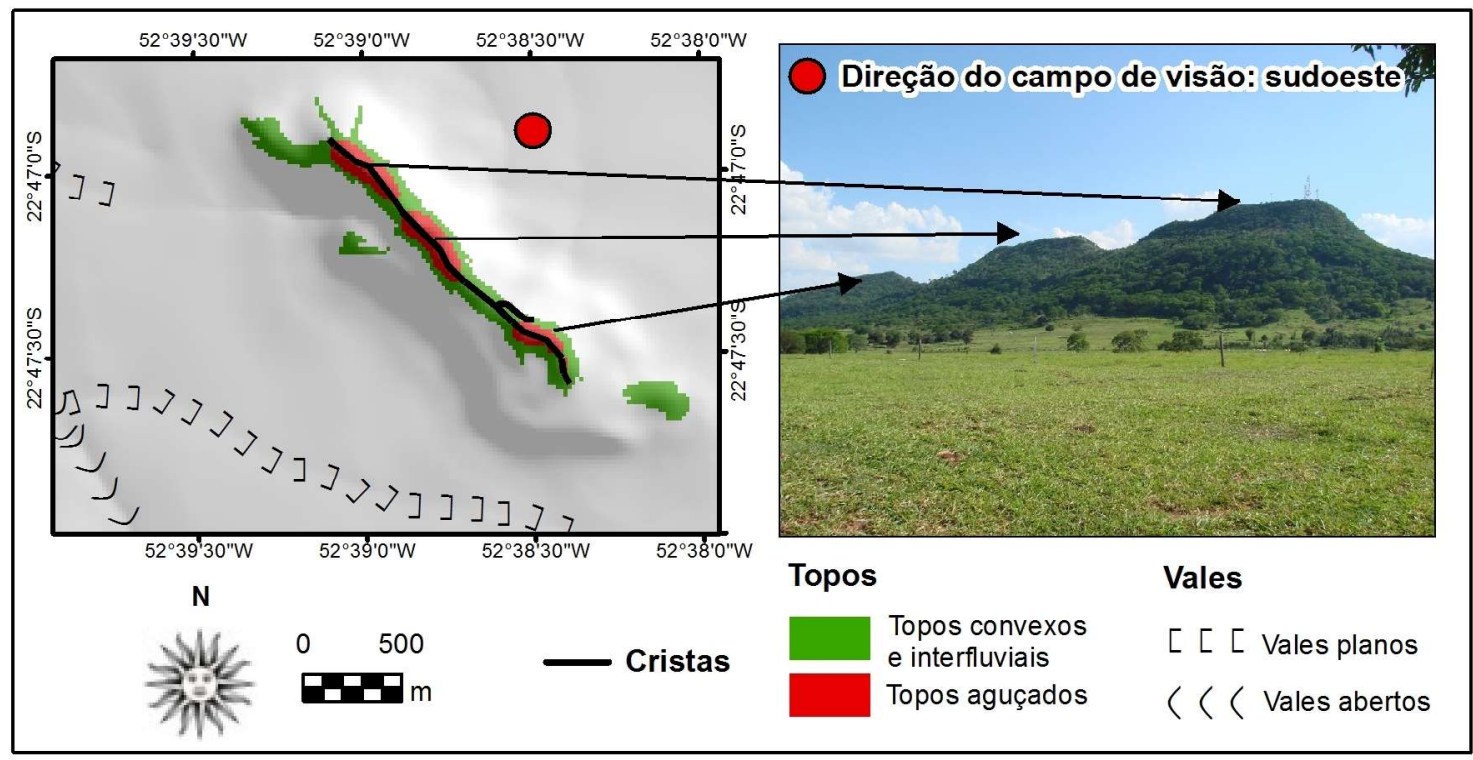

Figura 14 - Mapeamento nos Três Morrinhos

\section{CONCLUSÃO}

A aplicação da análise digital do relevo na modelagem dos topos, segmentos de cristas e vales, contemplando toda a diversidade geomorfológica do estado do Paraná, mostrou-se coerente às características do relevo - cujo mapeamento foi corroborado tanto pelos trabalhos de campo, in loco, quanto pelas interpretações regionais de publicações prévias. A proposta apresentada evidenciou o potencial de aplicação de técnicas geomorfométricas como ferramenta de apoio para trabalhos de mapeamento geomorfológico ou de estudos ambientais específicos, cuja parametrização confere a possibilidade de replicação metodológica e de diminuição da subjetividade nas etapas operacionais.

Referente à modelagem, conclui-se que: i) o processamento e a qualidade do modelo digital do terreno interferem diretamente nos resultados. Recomenda-se a utilização do interpolador pelo método Topogrid, a partir de base planialtimétrica, devido ao algoritmo enforcement aplicado na drenagem que favorece o cálculo da área de contribuição; ii) o cálculo e os valores de discretização dos atributos geomorfométricos devem apresentar rigor metodológico; iii) os parâmetros podem ser adaptados conforme os objetivos do mapeamento, ou seja, em função do fator de escala (têmporo-espacial) pretendido para o resultado final - quanto maior o tamanho do raio de análise de vizinhança dos atributos geomorfométricos, mais generalizada será a representação; iv) a inclusão de outros atributos geomorfométricos desponta como desdobramento da proposta apresentada, possibilitando o detalhamento das feições mapeadas com características geomorfológicas adicionais.

Quanto ao mapeamento propriamente dito, a aplicação da proposta demonstrou que o método pode ser utilizado em porções com distintos níveis de dissecação. Nas grandes planícies do estado, os vales planos e eventuais topos convexos foram devidamente mapeados; na região serrana, a modelagem detectou com exatidão os topos aguçados e segmentos de cristas associados às intrusões graníticas e os vales fechados característicos; nos três planaltos, o mapeamento das feições foi condizente às variações de litologia (efeitos da erosão diferencial na conformação do relevo) e às características das bacias hidrográficas.

\section{Agradecimentos}

Os autores agradecem à Coordenação de Aperfeiçoamento de Pessoal de Nível Superior (CAPES) pela bolsa de fomento de nível doutorado, concedida por meio do Programa de Pós-Graduação em Geografia da Universidade Federal do Paraná (PPGGEO-UFPR), e ao Conselho Nacional de Desenvolvimento Científico e Tecnológico ( $\mathrm{CNPq}$ ), pela disponibilização dos recursos financeiros que contribuíram com a realização do trabalho e os levantamentos de campo, por meio dos projetos "Mapeamento Geomorfológico do Estado do Paraná apoiado em análise digital do relevo, Processo $n^{\circ}$ 456244/2014-0, Apoio a Projetos de Pesquisa / MCTI/ 
CNPQ/Universal 14/2014 - Faixa A" e "Desenvolvimento metodológico e aplicações modelagem digital do terreno no mapeamento geomorfológico", Processo $n^{\circ}$ 434343/2018-8, Apoio a Projetos de Pesquisa / MCTI/ CNPQ/Universal 28/2018 - Faixa B.

\section{REFERÊNCIAS BIBLIOGRÁFICAS}

ALMEIDA, F. F. M.; CARNEIRO, C. D. R. Origem e evolução da Serra do Mar. Revista Brasileira de Geociências, n.28, v.2, p.135-150, 1998.

BIGARElla, J. J.; MOUSINHO, M. R.; SilVA, J. X. Pediplanos, pedimentos e seus depósitos correlativos no Brasil. Boletim Paranaense de Geografia, n. 16 e 17, p. 117-151, 1965.

BIGARELLA, J.J; BECKER, R.D; MATOS, D.J.; WERNER, A. A Serra do Mar e a porção oriental do Estado do Paraná: Um problema de segurança ambiental e nacional. Secretaria do Estado do Planejamento do Paraná: Curitiba. 1978.

BISHOP, M. P.; JAMES, A.; SHRODER, J. F.; WALSH, S. J. Geospatial technologies and geomorphological mapping: concepts, issues and research directions. Geomorphology, v. 137, p. 5-26, 2012.

COSTA, R. C. R.; BUSS, M. D.; ROSA, R. O. Geomorfologia. In: Levantamento de Recursos Naturais, Volume 35: folha SG.22 Curitiba, parte da folha SG.21 Asunción e folha SG.23 Iguape (Relatório técnico do Projeto RADAMBRASIL). Org.: Instituto Brasileiro de Geografia e Estatística (IBGE), Rio de Janeiro, 2005.

DEKAVALLA, M.; ARGIALAS, D. Object-based classification of global undersea topography and geomorphological features from the SRTM30_PLUS data. Geomorphology, v. 288, p. 66-82, 2017.

DIKAU, R. The Application of a Digital Relief Model to Landform Analysis in Geomorphology. In: RAPER, J. F (ed.). Three Dimensional Applications in Geographical Information Systems, London: Taylor \& Francis, p. 51-77, 1989.

DRAGUT, L.; EISANK, C. Object representations at multiple scales from digital elevation models. Geomorphology, v. 129, p. 183-189, 2011.

DRAGUT, L; BLASCHKE, T. Automated classification of landform elements using object-based image analysis. Geomorphology, v. 81, p. 330-344, 2006.

EL-SHEIMY, N.; VALEO, C.; HABIB, A. Digital Terrain Modelling: Acquisition, Manipulation and Applications. Artech
House, Inc., Norwood-Massachusetts. 2005.

ESRI. ArcGIS: Arcmap e extensão Spatial Analyst. Versão 10.1. Environmental Systems Research Institute, 2010.

EVANS, I. S. General geomorphometry, derivatives of altitude, and descriptive statistics. In: CHORLEY, R. J. (Ed.). Spatial analysis in geomorphology. London: Harper \& Row, Publishers, 1972.

GALLANT, J. C.; HUTCHINSON, M. F. Scale dependence in terrain analysis. Mathematics and Computers in Simulation, v. 43. p. 313-321, 1997.

GROHMANN, C. H.; SAWAKUCHI, A. O. Influence of cell size on volume calculation using digital terrain models: A case of coastal dune fields. Geomorphology, v.180-181, p. 130-136, 2013.

HENGL, T. Finding the right pixel size. Computers \& Geosciences 32, p. 1283-1298, 2006.

HENGL, T.; REUTER, H. I. (eds.) Geomorphometry Concepts, Software, Applications, Series Developments in Soil Science vol. 33, Amsterdam: Elsevier, pp. 3-30, 2009.

HUTCHINSON, M. F. A new procedure for gridding elevation and stream line data with automatic removal of spurious pits. Journal of Hydrology, 106, p. 211-272, 1989.

HUZITA, K.; KASAMA, T. Kôbe oyobi rinsetsu chiiki chisitu-zu, 1/50,000 (Geologic map of kobe and the adjacent area, 1/50.000). Geologic map. 3rd ed. Japão: Secretaria de Planejamento, Distrito Municipal de Kobe, 1977.

MAACK, R. R. Geografia Física do Estado do Paraná. 2. ed. Curitiba: Ed. Olympio, 1981.

MACMILLAN, R. A.; SHARY, P. A. Landform and landform elements in geomorphometry. In: HENGL, T.; REUTER, H. I. (eds.) Geomorphometry - Concepts, Software, Applications, Series Developments in Soil Science vol. 33, Amsterdam: Elsevier, pp. 227-254, 2009.

MILANI, E. J.; MELO, J. H. G.; SOUZA, P. A.; FERNANDES, L. A.; FRANCA, A. B.; Bacia do Paraná. Boletim de Geociências da Petrobrás, Rio de Janeiro, v. 15, n. 2, p. 265-287, 2007.

MINEROPAR - Minerais do Paraná S/A. Atlas geológico do estado do Paraná. 116 p. Curitiba, 2001.

NASCIMENTO, E. R.; SALAMUNI, E.; QUEIROZ, G. L.; SILVA, P. A. H.; FIORI, A. P. Evidências de determinação morfotectônica e neotectônica no relevo da Serra do Mar no estado do Paraná. Revista Brasileira de Geomorfologia, v.14, n.3, p. 287-299, 2013. 
PIKE, R. J. Geomorphometry - diversity in quantitative surface analysis. Progress in Physical Geography, v. 24, n. 1, p. 1-20, 2000.

PIKE, R. J. The geometric signature: quantifying landslideterrain types from digital elevation models. Mathematical Geology, v. 20, p. 491-511, 1988.

PIPAUD, I.; LEHMKUHL, F. Object-based delineation and classification of alluvial fans by application of mean-shift segmentation and support vector machines. Geomorphology, v. 293, p. 178-200, 2017.

RODRIGUEZ, F.; MAIRE, E.; COURJAULT-RAD'E, P.; DARROZES, J. The Black Top Hat function applied to a DEM: a tool to estimate recent incision in a mountainous watershed. (Estibère Watershed, Central Pyrenees). Geophysical Research Letters, v. 29, n. 6, 9-1 - 9-4, 2002.

ROSS, J. S. Registro cartográfico dos fatos geomorfológicos e a questão da taxonomia do relevo. Revista do Departamento de Geografia, v. 6, p. 17-29, 1992.

SALAMUNI, E.; NASCIMENTO, E. R.; SILVA, P. A. H.; OKAFIORI, C. Geomorfologia do município de Curitiba-PR. Revista Brasileira de Geomorfologia, v. 14, n. 4, p. 327-341, 2013.

SANTOS, L.J.C.; OKA-FIORI, C.; CANALI, N.E.; FIORI, A.P.; SILVEIRA, C.T.; SILVA, J.M.F.; ROSS, J. L.S. Mapeamento geomorfológico do Estado do Paraná. Revista Brasileira de Geomorfologia, n. 2, p. 3-12, 2006.

SCHMIDT, J.; ANDREW, R. Multi-scale landform characterization. Area, v. 37, p. 341-350, 2005.

SILVEIRA, C. T.; SILVEIRA, R. M. P. Índice de Posição Topográfica (IPT) para classificação geomorfométrica das formas de relevo no estado do Paraná - Brasil. Revista Ra'e Ga, v.41, p. $98-130,2017$.

SILVEIRA, C. T.; SILVEIRA, R. M. P.; TRENTIN, R.; ROBAINA, L. E. S. Classificação automatizada de elementos de relevo no estado do Paraná (Brasil) por meio da aplicação da proposta dos geomorphons. Revista Brasileira de Geomorfologia, v. 19, n.01, p. 33-57, 2018.

SILVEIRA, R. M. P.; SILVEIRA, C. T.; OKA-FIORI, C. Emprego de técnicas de inferência espacial para identificação de unidades de relevo apoiado em atributos topográficos e árvore de decisão. Revista Brasileira de Geomorfologia, v. 15, p. 87-101, 2014.

SILVEIRA, R. M. P.; SILVEIRA, C. T. Automated hierarchical classification of landforms in the state of Paraná supported by digital terrain modeling. Revista Brasileira de Geografia Física, v. 8, p. 1509-1523, 2015.

SILVEIRA, R. M. P.; SILVEIRA, C. T. Análise digital do relevo aplicada à cartografia geomorfológica da porção central da Serra do Mar Paranaense. Revista Brasileira de Geomorfologia, v. 17, n. 4, 615-629, 2016.

TARBOTON, D. G. A New Method for the Determination of Flow Directions and Contributing Areas in Grid Digital Elevation Models. Water Resources Research, v. 33, n. 2: p. 309-319, 1997.

WEISS, A. Topographic Position and Landforms Analysis. Poster presentation, ESRI User Conference, San Diego, CA, 2001.

WILSON, J. P.; GALLANT, J. C. (eds.). Terrain analysis: principles and applications. New York: John Wiley \& Sons, p.1-27, 2000. 